\title{
A Raman lidar at Maïdo Observatory (Reunion Island) to measure water vapor in the troposphere and lower stratosphere: calibration and validation
}

Hélène Vérèmes ${ }^{(1,2)}$, Guillaume Payen ${ }^{2}$, Philippe Keckhut ${ }^{3}$, Valentin Duflot ${ }^{(1,2)}$, Jean-Luc Baray ${ }^{4}$, Jean-

5 Pierre Cammas ${ }^{(1,2)}$, Jimmy Leclair de Bellevue ${ }^{1}$, Stéphanie Evan ${ }^{1}$, Françoise Posny ${ }^{(1,2)}$, Franck Gabarrot $^{2}$, Jean-Marc Metzger ${ }^{2}$, Nicolas Marquestaut ${ }^{2}$, Susanne Meier ${ }^{5}$, Holger Vömel ${ }^{6}$ and Ruud Dirksen $^{5}$

${ }^{1}$ Laboratoire de l'Atmosphère et des Cyclones, UMR8105, Saint-Denis de La Réunion, France ${ }^{2}$ Observatoire des Sciences de l'Univers de La Réunion, UMS3365, Saint-Denis de la Réunion, France

$10{ }^{3}$ Laboratoire ATmosphères, Milieux, Observations Spatiales-IPSL, UMR8190 CNRS, UVSQ, UPMC, Guyancourt, France

${ }^{4}$ Laboratoire de Météorologie Physique, UMR6016, Observatoire de Physique du Globe de ClermontFerrand, Université Clermont Auvergne, Clermont-Ferrand, France

${ }^{5}$ Deutscher Wetterdienst, Meteorological Observatory Lindenberg, Lindenberg, Germany

$15{ }^{6}$ National Center for Atmospheric Research, Boulder, CO, USA

Correspondence to: Hélène Vérèmes (helene.veremes@univ-reunion.fr)

\begin{abstract}
The Maïdo high-altitude observatory located in Reunion Island $\left(21^{\circ} \mathrm{S}, 55.5^{\circ} \mathrm{E}\right)$ is equipped with Lidar1200, an innovative Raman lidar designed to measure the water vapor mixing ratio in the troposphere and the lower stratosphere. The

20 calibration methodology is based on a GNSS (Global Navigation Satellite System) IWV (Integrated Water Vapor) dataset and lamp measurements. The mean relative standard error on the calibration coefficient is around $2.7 \%$. Two years of lidar water vapor measurements from November 2013 to October 2015 are now processed. By comparing CFH (Cryogenic Frost point Hygrometer) radiosonde profiles with the Raman lidar profiles, the ability of the lidar to provide accurate measurements is possible up to $22 \mathrm{~km}$. The ability of measuring water vapor mixing ratios of a few ppmv in the lower stratosphere is

25 demonstrated with a 48-hours integration time period, an absolute error lower than 0.8 ppmv and a relative error less than $20 \%$. This Raman lidar is dedicated to provide regular profiles of water vapor measurements with a high vertical resolution and low uncertainties to international networks; in the wider interest of research on stratosphere-troposphere exchange processes and on the long-term survey of water vapor in the upper troposphere and lower stratosphere in the Southern Hemisphere. A strategy of data sampling and filtering is proposed to meet these objectives with regard to the altitude range requested. 10-min time

30 integration and $65-90 \mathrm{~m}$ vertical resolution ensure a vertical profile reaching $10 \mathrm{~km}$, but more than 2800 minutes and a vertical resolution of 150-1300 m are necessary to reach the lower stratosphere with an uncertainty less than $20 \%$.
\end{abstract}

\section{1 Introduction}

To monitor potential climate changes, observations of essential climate variables (ECV) such as atmospheric water vapor (Bojinski et al., 2014) are necessary. Long-term series allow the international community to progress on important

35 climatological issues, such as the contributions of stratospheric water vapor to decadal changes in the rate of global warming (Solomon et al., 2010). Selection criteria are important for the certification of networks. These criteria include: long-term stability and regularity. When supplying the databases, very precise and detailed metadata files of the physical quantities have to be provided. And most importantly, an uncertainty has to be associated to the data. This last exercise is realized through the examination of the data processing algorithms and calibration methodologies. This rigor is essential to monitor efficiently the 
atmosphere and climate changes (Immler et al., 2010). One of the challenging ECV to measure is water vapor mainly in the upper troposphere and lower stratosphere (GCOS, 2003). Water vapor is the main greenhouse gas. The factors influencing its spatio-temporal variability are various: convection, precipitations, temperature (Kennett and Toumi, 2005), transport and dynamical processes from eddies to synoptic scale events. The residence time of the water vapor in the atmosphere is several

5 days to weeks (Trenberth, 1998; Läderach and Sodemann, 2016). Nevertheless, its temporal variability can be high at a scale of dozens of minutes, and its spatial variability can be less than one kilometer (Vogelmann et al., 2011, 2015). To track, monitor and set water vapor trends in the troposphere and in the lower stratosphere, it is essential that dense and regular measurements supply global networks as NDACC (Network for the Detection of Atmospheric Composition Change; Kurylo and Solomon, 1990) and GRUAN (GCOS Reference Upper Air Network; Seidel et al., 2009, Bodeker et al., 2015). The

10 NDACC community gives a stronger focus on the study of the dynamics and on chemical processes of the UT/LS (Upper Troposphere/Lower Stratosphere) that represents a key area of exchanges between the two main layers. The characterization of the water vapor in the troposphere and more specifically in the UT/LS is one of the scientific goals of GRUAN (Seidel et al., 2009). This network ensures the quality and the density of stations in order to face this scientific issue. It is not sufficient to ensure a global covering and frequent measurements, it is also essential to trust measurements quality and accuracy up to 15 the lower stratosphere.

Water vapor measurement techniques are various: in situ or remote sensing, ground based, airborne or space based (Wulfmeyer et al., 2015). A limited number of instruments is able to accurately measure the vertical distribution of the water vapor in the UT/LS. The sondes with a capacitive sensor are not reliable enough in the stratosphere (WMO, 2011). Few of these sondes measure water vapor in the subtropical upper troposphere. Among the radiosondes, the hygrometers are the most

20 efficient. The CFH (Cryogenic Frost point Hygrometer) exhibits accuracy better than $4 \%$ in the tropical lower stratosphere, to $9 \%$ around the tropopause and about $10 \%$ at $28 \mathrm{~km}$ (Vömel et al., 2007). They are shown to be good in the UT/LS (Vömel et al., 2007). Nevertheless, the CFH are rarely launched on a routine basis at these stations mainly because of their cost. GRUAN recommends to launch at least one radiosounding per month with a CFH or similar sondes (Bodeker et al., 2015). Regarding global covering satellites measurements, the MLS (Microwave Limb Sounder) is very accurate (Read et al., 2007) and even 25 the most efficient in the lower stratosphere. Between 100 and $121 \mathrm{hPa}$, the accuracy (bias) of the MLS is around 15-20\% (8$12 \%)$. At $83 \mathrm{hPa}$, it is reduced to $10 \%(7 \%)$. The detection threshold is extremely low: $0.1 \mathrm{ppmv}$ above $150 \mathrm{hPa}$ (Livesey et al., 2011). Few of the others on board satellite instruments, in operation today, can measure in the vicinity of the tropopause and even less the lower stratosphere. If the accuracy of MLS is very high, its horizontal resolution is poor and its vertical resolution is of the order of 2-3 km. Other remote sensing measurements (ground-based or on board instruments) are based on

30 the lidar (LIght Detection And Ranging) systems. Water vapor profiles can also be measured by two lidar techniques: DIAL (DIfferential Absorption Lidar) and Raman lidar. The overview of the capacities of the ground-based DIAL lidar by Wulfmeyer et al. (2015) reports that they have a range of $10 \mathrm{~km}$ (for night measurements) with a vertical resolution from 15 to $900 \mathrm{~m}$ and an accuracy of 1 to $10 \%$ (depending on the altitude). No calibration factor is needed, avoiding a supplementary uncertainty. Nevertheless, the DIAL measurement is limited in altitude because of the large absorption in the lower troposphere in case of 35 high water vapor (Turner et al., 2000).

In opposite, some of the NDACC Raman lidars (all ground-based) are able to reach the UT/LS as the Purple Crow Lidar (Canada; Argall et al., 2007), the Table Mountain Facility (United-States; Leblanc et al., 2012) and Tor Vergata system (Italy) (Dionisi et al., 2010) lidars. Nevertheless, the altitude of the tropopause is lower in such mid-latitude areas than in the (sub)tropics. The Mauna Loa Observatory Raman lidar is able to reach $15 \mathrm{~km}$ on a routine basis (Barnes et al., 2008). Raman

40 lidar could be able to measure water vapor in the tropical UT/LS but such performances remain to be demonstrated and quantified precisely. The calibration of the data of the Raman lidars is important for the stability of the measurement on a short and long-term basis (Sherlock et al., 1999a) and will induce an uncertainty of at least 5\% (Wandiger et al., 2005) no matter the complementary measurement used. Calibration is typically done using water vapor profiles from radiosoundings (Sherlock et 
al., 1999a). All the Raman water vapor lidars of the NDACC used Vaisala sondes to calibrate their database. Different measurements have been tested and intercompared to calibrate the data (GNSS, radiometer and optimized matching methods when using radiosoundings) during different campaigns: DéméVap (Développements Méthodologiques pour le sondage de la Vapeur d'eau dans l'atmosphère; Bock et al., 2013), MOHAVE (Measurements Of Humidity in the Atmosphere and Validation

5 Experiments; Leblanc et al., 2012), and HOPE (HD(CP)² Observational Prototype Experiment; Foth et al., 2015). The uncertainty on the calibration factor calculated by the different instruments was between 5 to $10 \%$. One of the conclusions of these studies is that the GNSS IWV (Integrated Water Vapor) is appropriate to calibrate the Raman lidar, the resulting uncertainty being around 7\% during DéMéVap (Bock et al., 2013). The key point to use the GNSS IWV for the calibration of Raman lidar water vapor measurements is the lidar's ability to retrieve the total water vapor column to ensure that the same

10 columns are probed by the 2 instruments; in other words: whether or not the lidar is able to measure water vapor close enough to the ground.

In Reunion Island, a new Raman lidar has been designed to monitor simultaneously the water vapor from the ground up to the lower stratosphere and the temperature in the stratosphere and the mesosphere. The system is an updated version of the former Rayleigh-Mie-Raman system in operation at Saint-Denis (Reunion Island) between 2002 and 2010. Some critical

15 points have been addressed in the upgrade, including fluorescence, power and parallax effects, in order to optimize the configuration of the system (Hoareau et al., 2012; Sherlock et al., 1999b). In October 2012, this new lidar system has been set up at a higher altitude: the Maïdo facility located at $2160 \mathrm{~m}$ asl (Baray et al., 2013). At the same time, most of the instruments of the OPAR (Observatoire de Physique de l'Atmosphère de la Réunion) moved to the observatory. In order to optimize the instrumental configuration and to evaluate a first set of data, two measurement campaigns were organized: MALICCA-1

20 (MAïdo LIdar Calibration CAmpaign) in April 2013 (Keckhut et al., 2015) and MALICCA-2 in November 2013. The MALICCA-1 dataset shows a good agreement between the water vapor data measured by the lidar and those measured by the other instruments (Vaisala RS92, MLS, Dionisi et al., 2015). The relative difference between the lidar profiles and 15 simultaneous radiosoundings (Vaisala RS92) was lower than 10\% for the lower and middle troposphere and between 10 and $20 \%$ for the upper troposphere. Two integration methods have been tested: 240 minutes with an uncertainty of 2 ppmv between

2517 and $20 \mathrm{~km}$, and a monthly integration (i.e. an integration of $\sim 1920 \mathrm{~min}$ ) with an uncertainty of $1 \mathrm{ppmv}$ at $20 \mathrm{~km}$, which demonstrates the ability of the lidar to measure quantities of only few ppmv in the UT/LS (Dionisi et al., 2015). The monthly mean profile of water vapor based on MLS data agrees well with the mean lidar profile of MALICCA-1 in the lower stratosphere. The main conclusions of Dionisi et al. (2015), based on two weeks of intensive measurements during a campaign, need to be extended on a longer 2-years period of routine measurement and to be reviewed. GNSS data can be used to calibrate

30 the water vapor mixing ratio profiles but it is still necessary to develop a robust methodology of calibration feasible on long term, as required for participation in international networks such as NDACC. It is noteworthy that this Maïdo Raman water vapor lidar (called hereafter "Lidar1200") was recently provisionally affiliated within the NDACC. The conclusive affiliation occurs when absence of fluorescence and a stable calibration method are both demonstrated using validation campaigns involving frost-point hygrometer measurements.

The main objectives of this paper are to assess the ability of this lidar to monitor the water vapor in the lower tropical stratosphere on a long-term basis and to introduce its 2-years dataset of water vapor profiles. We will describe the instrument, the data processing and the calibration methodology. A routine calibration methodology, based on GNSS observations, has been developed in order to improve the reliability of the calibration coefficient and the robustness of the measurements. This methodology is detailed in Sect. 2. The validation of the profiles by comparing the lidar data with CFH radiosoundings will

40 be presented in the Sect. 3. The evaluation of the performances of the instrument is detailed in Sect. 4 from fine scale structures detection to the potential establishment of climatologies and then trends in the UT/LS. Finally, an overview of the 2-years dataset is given (Sect. 5). 
Atmos. Meas. Tech. Discuss., doi:10.5194/amt-2017-32, 2017

Atmospheric

Manuscript under review for journal Atmos. Meas. Tech.

Discussion started: 4 April 2017

(c) Author(s) 2017. CC-BY 3.0 License.

\section{Description of the system, the data processing and the calibration methodology}

\subsection{Routine Raman system measurements}

Before being transferred to the Maïdo Observatory in 2012, the Raman water vapor lidar operated in the north of Reunion Island, at Saint-Denis, at sea level (Hoareau et al., 2012). The system was upgraded to work at $355 \mathrm{~nm}$, a more efficient

5 wavelength than $532 \mathrm{~nm}$ (Dionisi et al., 2015). Laser pulses are generated by two Quanta Ray Nd:Yag lasers with a repetition rate of $30 \mathrm{~Hz}$. The use of two lasers increases significantly the power of the signal. They are synchronized through a pulse generator cube with an uncertainty less than $20 \mathrm{~ns}$. The emitting pulse of each laser has an energy of $375 \mathrm{~mJ}$. pulse ${ }^{-1}$ and a duration of $9 \mathrm{~ns}$ and they are gathered through a polarization cube. The geometry for transmitter and receiver is coaxial for three different reasons: i) to avoid parallax effects, ii) to extend the measurements down to the ground and iii) to facilitate the

10 alignment. The backscattered signal is collected by a Newtonian telescope with a primary mirror of $1.2 \mathrm{~m}$ diameter. When collecting small Raman scattering by water vapor compared with the large elastic scattering able to generate fluorescence, the use of an optical fiber is an important issue. It has been shown that the fluorescence in such cables can cause systematic biases (Sherlock et al., 1999b). Thus, no optical fiber is used. A spectrometer is used directly after this telescope to separate the Raman and Rayleigh signals. Thanks to a diaphragm field stop at the entrance of the spectrometer, the field of view (FOV) of

15 the system is adjustable (from 3.0 to $0.5 \mathrm{mrad}$ ). On a routine basis, a $2 \mathrm{~mm}$ FOV ( $0.5 \mathrm{mrad}$ ) allows the reduction of the background light, limits the photo-counting saturation from low altitude scattering. The overlap factor is identical for both channels. Thus, water vapor profiles can be retrieved down to the ground. Details on the different tests realized during MALICCA that led to the final choice of the operational optical configuration are given in Dionisi et al. (2015). The spectrometer is composed of dichroic beam splitters and interference filters which separate the backscattered light. Hamamatsu

20 miniature PMT and Licel transient recorders are used for the photo detection and data acquisition in photon counting.

\subsection{Water vapor data processing}

The initial data processing algorithm (Dionisi et al., 2015) has been upgraded to version 2.3.1 to include the identification and quantification of the uncertainties and the vertical resolution determination.

\subsubsection{Identification and quantification of the uncertainties}

25 A full analysis of identification of the sources and quantification of the different uncertainties has been carried out. The total absolute error ( $\triangle \mathrm{WVMR}$ ) on the calibrated profiles (WVMR) is calculated as followed:

$$
\frac{\Delta W V M R}{W V M R}=\sqrt{\left(\frac{d w}{w}\right)^{2}+\left(\frac{d C}{C}\right)^{2}+\left(\frac{d \Gamma}{\Gamma}\right)^{2}}
$$

where $\left(\frac{d w}{w}\right)$ is the relative error associated with the statistical error of the detectors (PMT), $\left(\frac{d C}{C}\right)$ is the uncertainty due to the

30 calibration coefficient and $\left(\frac{d \Gamma}{\Gamma}\right)$ is due to the extinction coefficient term. The different sources of the assumed uncorrelated statistical error are associated with the counting of the number of photons collected by the detector for the water vapor and nitrogen channels depending on the altitude. The sources of systematic errors are the determination of the calibration coefficient, and of the cross-sections at the wavelengths of the water vapor and nitrogen Raman channels. Finally, the molecular extinction/density can be retrieved by either a model, a climatology or measurements with a good accuracy regarding the

35 relatively weak variability of the atmospheric density at a given level and is based on the pressure and temperature profiles. For the Lidar1200 data, we identify that the main uncertainties are:

- the uncertainty on the model of the density profile (extracted from a climatology) that has been arbitrarily fixed to 

suppose that the uncertainty due to aerosols on the factor of transmission is negligible compared to the uncertainty on the molecular transmission. Indeed, the effect of aerosols on Raman channels in the UV is low.

- the uncertainty on the calibration ranges from $1.6 \%$ to $3.6 \%$ for the $2013-2015$ period. The mean standard error is about $2.7 \%$. This will be developed in Sect. 2.3. It is independent of the altitude.

- the statistical error has the more important contribution, it increases with the altitude and depends on different characteristics of the instrument and the signal varying from one measurement to another (integration time, background). This error will drive the reliability of the data in the UT/LS.

The total error is directly influenced by the calibration and the quality of the measurements. It varies because of the statistical

10 and systematic errors in the lower troposphere. In the middle troposphere up to the lower stratosphere, the statistical errors determine the reliability of the profiles. The uncertainty depends strongly on the integration time and the filtering of the signal. Thus, it is important to use a suitable filter regarding the vertical resolution and the order of magnitude of the total error.

\subsubsection{Vertical resolution}

The vertical resolution of the raw data is $15 \mathrm{~m}$. Data are smoothed with a filter using the Blackman coefficients: thus, the final

15 resolution is different from the initial resolution. The number of points of the filter varies with the altitude, the number increasing with altitude to compensate the signal to noise ratio (SNR) decrease. The NDACC has formulated and adopted two standardized definitions for the calculation of the final vertical resolution for its lidars based on 1) cut-off frequency of digital filters (used here) or 2) the full-width at half-maximum of a finite impulse response (Leblanc et al., 2016). Based on the number of points used for the filter to vertically average the data, the vertical resolutions (Fig. 1) that can be derived from these

20 definitions are 100-200 $\mathrm{m}$ in the lowest layers, $500 \mathrm{~m}$ in the mid-troposphere, $600 \mathrm{~m}$ in the upper troposphere and $700-750 \mathrm{~m}$ in the lower stratosphere, for a filter using the Blackman coefficients reaching 121 points at $20 \mathrm{~km}$ asl.

To summarize, the uncalibrated profiles are processed with a vertical resolution, and a time integration depending on the water vapor variability at several levels. In order to convert the backscattered radiation profiles into water vapor mixing ratio profiles, it is necessary to calculate afterward a calibration coefficient from water vapor column ancillary data. The

25 specific calibration methodology that has been developed for the Lidar1200 is described in the next subsection. The validation and evaluation of the performances of the lidar is detailed in Sect. 3 and 4.

\subsection{Calibration methodology}

\subsubsection{The GNSS technique}

The GPS and GLONASS (GLObal NAvigation Satellite System) satellite constellations signals are collected by a ground-

30 based receiver. With respect to propagation in a vacuum, the signal travelling between a GPS satellite (altitude of 20,200 km) and a ground-based receiver is delayed by atmospheric constituents (dry air, and water vapor). To determine the IWV from GNSS data, the total atmospheric zenithal delay (ZTD) is estimated. Using surface pressure information, the ZTD can be divided into a hydrostatic term, i.e. the Zenithal Hydrostatic delay (ZHD or so-called dry delay) calculated through the Saastamoinen formula (Saastamoinen, 1972). The hydrostatic delay, which is derived by applying the condition that

35 hydrostatic equilibrium is satisfied, depends on the total weight of the atmosphere above. The difference term accounts for the Zenithal Wet Delay (ZWD, so-called wet delay). The wet delay is the propagation delay experienced by GPS signals due mainly to water vapor abundance. ZWD is converted into IWV, using surface temperature and empirical formulas (Bevis et al., 1992; Emardson and Derks, 2000). The raw data inversion process and its uncertainty is mainly controlled by mapping the Slant Total Delay (STD, in any direction) to the delay at zenith to which horizontal gradients (North-South and East-West) are 40 added.

Many authors assessed the accuracy in GPS IWV, based on comparisons with radiosondes, sun photometers, 

These techniques agree for about 1-2 kg. $\mathrm{m}^{-2}$ for typical values between 5 and $30 \mathrm{~kg} . \mathrm{m}^{-2}$. In practical, an accuracy ranging from 0.5 to $2.5 \mathrm{~kg} . \mathrm{m}^{-2}$ have been observed regarding the localization of the measurements but few sources of uncertainties still need to be investigated (Bock et al., 2013).

5 A TRIMBLE-NETR9 receiver (MAIG) has been installed at the Maïdo Observatory in 2013 in order to receive the GNSS data (see http://rgp.ign.fr/STATIONS/\#MAIG). The GNSS network used to calculate IWV above the station includes 20 other local stations disseminated over the island, and in order to ensure efficiently high numbers of baselines for the differential data processing through GAMIT software v10.32 (King and Bock, 2007), 15 overseas stations in the Indian Ocean are included. The typical cutoff elevation angle is fixed to $10^{\circ}$ to ensure the most local sounded area of water vapor as possible.

10 Currently, the database produces hourly IWV, 24 hours at the Observatory elevation. The precision is in agreement with the literature and is about 1 to $2 \mathrm{~mm}$. The complete evaluation of the uncertainty will be further detailed in a future publication.

\subsubsection{Relevance of the use of GNSS IWV for calibration}

The raw data of the Lidar1200 need to be calibrated. Two ancillary measurements might be used: radiosondes or GNSS. The main concern for the calibration is to be able to have collocated and simultaneous measurements on a routine basis. We consider

15 that space-time criteria for colocation do not match between the biweekly normal operation of the Raman lidar (15:00-21:00 UTC) at the Maïdo Observatory and the daily 12:00 UTC radiosounding (Météo-France) or the weekly 10:00 UTC ozone radiosounding (NDACC/SHADOZ OPAR site) based at the airport which is $20 \mathrm{~km}$ from the Maïdo Observatory. Launching two sondes per week from the Maïdo Observatory would have a significant financial and logistical cost. These are the main reasons in choosing the GNSS for the calibration. GNSS measurements are abundant, collocated and simultaneous to the lidar

20 data. IWV is calculated each hour providing that the uncertainty of the estimated ZTD by GAMIT remains below the standard threshold of $30 \mathrm{~mm}$ which occurs around $95 \%$ of the time. The other reasons are the independence of the lidar series regarding the radiosoundings series that have revealed some discontinuities in the past due to the relative humidity sensor calibration and the hourly basis availability of the GNSS data. Since 2013, the lidar profiles can be calibrated using integrated water vapor columns obtained from these GNSS measurements.

As stated earlier, the main prerequisite to the use of GNSS IWV to calibrate Raman lidar water vapor measurements is the ability of the lidar to actually probe the IWV, i.e. to start measurements at the ground level. The emission and reception parts being coaxial, the full recovering altitude of the lidar is very low. The recovering of the laser beam with the field of view of the telescope is partial from the ground (i.e. $2.2 \mathrm{~km}$ asl) to $4 \mathrm{~km}$ asl. The data processing is based on a ratio between both channels $\left(\mathrm{H}_{2} \mathrm{O}\right.$ and $\left.\mathrm{N}_{2}\right)$, there is no correction associated to the recovering. The first available point of the lidar water vapor

30 profile is $15 \mathrm{~m}$ above the instrument (vertical resolution of the raw data). This somehow propitious, but expected, result can be explained by the contribution of the coaxial geometry of the optical design, the FOV, and the diameter of the receiving telescope. One concern regarding the use of total column is that sometimes the lidar profile could not reach the lower stratosphere and exhibits a partial column. A calculation performed on the vertically averaged water vapor data of the CFH sondes launched during the MORGANE (Maïdo ObservatoRy Gas and Aerosol NDACC Experiment) campaign (Reunion

35 Island, May 2015), shows that, up to $5 \mathrm{~km}$, the cumulated water vapor represents $90 \%$ of the total column; above $10 \mathrm{~km}, 99 \%$ of the whole column is contained. Thus, it appears sufficient to use IWV total columns to calibrate the Lidar1200 water vapor profiles when the range of the profile is higher than $10 \mathrm{~km}$.

\subsubsection{Description of the methodology}

Usually a calibration coefficient is the ratio between a reference instrument, here it is the GNSS IWV, and the uncalibrated

40 lidar IWV data. In this section, the hourly calibration coefficient, named "hourly coefficient" represents the ratio between the GNSS IWV calculated on 1-hour and the lidar IWV integrated on the same temporal extent. The averages of the hourly 

correspond to the coefficient calculated with the methodology described below, it represents the coefficient used to calibrate the Lidar1200 water vapor dataset for supplying the national and international networks. If no instrumental change occurs, the calibration coefficient is supposed to be almost constant.

To determine the calibration coefficient of the Lidar1200's water vapor profiles, the ratios between the GNSS and lidar IWV data are compared. The temporal coincidence between the datasets consists of taking the hourly GNSS IWV and integrating the lidar data on a 1-hour window around the hourly mean GNSS. The principle can be illustrated as followed: if the GNSS measurement corresponds to 18:00 LT, the lidar data are integrated between 17:30 and 18:25 LT (with a minimum of 45 minutes). The time series of the nightly coefficients (Fig. 2) has been used in order to identify the periods with a quasi-

10 constant ratio. The nightly coefficient varies in time, probably due to the fact that the integration methods are different. Even if the GNSS and the lidar are collocated, they do not measure exactly the same volume of water vapor (in space and in time). Nevertheless, periods of quasi-stationarity of the nightly coefficient can be defined inside periods in which the lidar was considered as instrumentally stable. The average nightly coefficient of each quasi-stationary period is considered as the calibration coefficient of the associated profiles. Nevertheless, for the near-real time treatment, the profile is calibrated with

15 the former validated coefficient. It remains necessary to check if there are instrumental changes in order to detect possible alteration of the coefficient, and to recalculate it if required to compile the final dataset. At the beginning of each night of measurements, a systematic lamp measurement is made in order to detect potential sudden instrumental changes due to nonidentified causes. The lamp measurement allows to look at the changes that occur only on the reception part of the system. The lamp measurement consists in the emission of a white light on the telescope which lightens the sensors. An acquisition is

20 launched, the information extracted is "white noise". This noise is averaged all over the altitude range and for all the channels. Finally, the lamp measurement value corresponds to the ratio of the signal of the Raman $\mathrm{H}_{2} \mathrm{O}$ channel and the Raman $\mathrm{N}_{2}$ channel. This value is independent from the altitude and is impacted by the laser power, the losses due to the reception optics and the efficiency of the sensors. Some of the instrumental changes affecting the calibration coefficient are known. The logbook can be checked to reduce non-automatic detections of instrumental changes. With hindsight on the dataset, the

25 identification of the periods with a stable nightly/hourly coefficient allows to overcome the problem of automatic detection of instrumental change. Once the periods are identified, the calibration coefficients are validated and, thus, the data can be calibrated and used for geophysical purposes.

Figure 2 shows the time series of the nightly coefficients and the 10 associated quasi-stationary periods, with lamp measurements superimposed. An analysis of the lamp measurements leads to the identification of one very short quasi-

30 stationary period associated with changes of the calibration coefficient: P03 to P04 in June 2014 (change of the interference filter of the $407 \mathrm{~nm}$ channel). All remaining quasi-stationary periods involving a new calibration coefficient have been identified thanks to the logbook: realignments of the optics of the lidar and interventions on the lasers. The 2-years database has been calibrated (Table 1) with the exception of the third period ( $\mathrm{P} 03$ ) which corresponds to a training session of the technicians and scientists on the alignment of the water vapor lidar, which was part of a training exercise dedicated to preparation for the MORGANE campaign.

\subsubsection{Comparison with other calibration devices}

The previous subsection has shown that the GNSS technique provides a suitable methodology to calibrate the Lidar1200. To evaluate how suitable is this methodology, other generally used calibration techniques have been compared, in particular the use of radiosoundings. The first exercise consists of comparing the GNSS-based calibration coefficients with those derived

40 from the other techniques. The most common technique to calibrate the lidar raw profiles is the use of a coincident (temporally and when possible geographically) radiosounding. Dionisi et al. (2015) showed encouraging results for the use of GNSS IWVbased on a first comparison with the use of Vaisala RS92 for calibrating the profiles during MALICCA-1 campaign. To 

comparisons. The MORGANE campaign involving CFH, Vaisala RS92 and RS41 and Modem M10 sondes launched from the Maïdo Observatory concomitantly with GNSS and lidar measurements provided an interesting opportunity. The comparison method was based on a daily calibration of the lidar profiles using a GNSS or a sonde reference profile, i.e. the ratio of the

5 reference profiles with the uncalibrated lidar profile of the night at an altitude between 3 and $4 \mathrm{~km}$. This range of altitude has been chosen because the difference between the reference and the uncalibrated profiles was the weakest on average. This method produces a time series of daily calibration coefficients for the duration of the campaign for each type of sonde and for the GNSS (Fig. 3). Only the results for the nights when the water vapor lidar was operating and when a radiosounding has been performed simultaneously are shown. Note that the period of study includes the prolongation of the MORGANE

10 campaign in June justified by the need of supplementary ozone measurements. The mean GNSS calibration coefficient on the period is 157 , the one by CFH is 170, 149 for the RS92 and RS41, and 135 for the M10 (Fig. 3). The dry bias of the Vaisala and Modem sondes is known (Miloshevich et al., 2006, Bock et al., 2013). The calibration coefficient characterized by GNSS calculated with the routine methodology of the calibration of the Lidar1200 is $155( \pm 32)$. All the coefficients derived from the different sondes are included in the standard deviation interval of the routine based calculation (123-187). The mean value of

15 the coefficient derived from GNSS sits between the one derived from the capacitive sensor technique and the one derived from the CFH technique (Fig. 3). Thus, it is confirmed here that the GNSS technique is as suitable as radiosoundings for the calibration of the water vapor profiles of the Lidar1200.

\subsubsection{Limits of the methodology}

The accuracy of the GNSS calibration method is reduced during the dry season. The total column calculated using the vertical

20 profile measured by the $\mathrm{CFH}$ sonde and those obtained by GNSS show an average difference of $2 \mathrm{~mm}$. If the CFH is considered as the reference instrument, the uncertainty on the GNSS IWV appeared to be of around 1-2 mm, which is in agreement with the values of accuracy in the literature. Figure 4 represents the distribution of the measurements of the GNSS IWV with season at the Maïdo Observatory. During the summer and the autumn, the distributions are monomodal and imply the largest IWV (30-35 mm). During the winter and the spring, most common IWV are around 3-5 $\mathrm{mm}$. The austral winter has the driest

25 atmosphere, the IWV can be lower than $3 \mathrm{~mm}$. Thus, the uncertainty on the calibration becomes too large during that season in particular. This effect is specific to the subtropical climate regime in Reunion Island area, where very dry conditions are observed above $5 \mathrm{~km}$ altitude from July to September. If any change occurs, the continuity is insured by the lamp measurements. Calibration would be improved by launching a few radiosoundings in winter from the Maido Observatory to confirm, or determine, the calibration coefficient of the water vapor profiles during these dry conditions.

\section{$30 \quad$ 2.3.6 Systematic error or bias on the measurement}

Calibration coefficients are calculated on the average of the individual nightly coefficients over the quasi-stationary periods. The uncertainty on the calibration coefficient of each period can be estimated by the standard deviation of the nightly coefficients of the associated quasi-stationary period. The uncertainty of the calibration coefficient can be estimated by the standard deviation of the nightly coefficients. If the calibration is considered as stationary and only due to random fluctuations,

35 the uncertainty on the calibration coefficient of each period is mainly due to the term corresponding to the standard deviation divided by the square of the number of nightly calibration coefficients. The uncertainty of the calibration coefficient varies between 1.6 and 3.6\% between 2013 and 2015 (Table 1). The mean standard error on the calibration for the whole dataset is $2.7 \%$.

An original methodology for Raman lidar calibration has been designed with GNSS measurements. The very low

40 values of the standard calibration uncertainty guarantee a high reliability of the coefficient calibration. The methodology minimizes the calibration uncertainty and its use has been successfully tested on the 2-years dataset of the Lidar1200. The 
Atmos. Meas. Tech. Discuss., doi:10.5194/amt-2017-32, 2017

Manuscript under review for journal Atmos. Meas. Tech.

Discussion started: 4 April 2017

(c) Author(s) 2017. CC-BY 3.0 License.

methodology will be further validated thanks to instrumental comparisons presented in Sect. 3.

\section{Validation of the Lidar1200 dataset: comparison with CFH sondes data during measurement campaigns}

\subsection{Description of the measurement campaigns}

The Lidar1200 was involved in 5 campaigns (Fig. 5): MALICCA-1 and 2 in 2013, LIDEOLE-1 in November 2014,

5 MORGANE in May 2015 and LIDEOLE-2 in September 2015. MALICCA-1 (described in Sect. 1) has been followed by a complementary campaign; MALICCA-2, during which the last technical details have been tested and the instrument has been robustly configurated for the routine measurements. The campaign LIDEOLE-1 was focused on the Doppler wind lidar and has involved intensive measurements of all lidars at the observatory. A first launch of CFH sonde was performed in November 2014 which allowed a comparison with the water vapor data of the Raman lidar. The campaign of the largest program in which

10 the Lidar1200 was involved is MORGANE. It took place between 27 April to 29 May 2015, including the technical preparation and the instrumental comparisons. Nine laboratories were involved and about fifteen instruments were operated. The main goals of that campaign were:

- blind comparisons between the temperature, water vapor and ozone lidars of the observatory (Baray et al., 2013) and the NASA/GSFC STROZ mobile lidar (McGee et al., 1991; Sullivan et al., 2014) brought to Reunion Island for the campaign

- daytime and nighttime meteorological radiosoundings to work on technical issues associated to GRUAN

- the study of atmospheric processes associated to the composition of the UT/LS and to the atmospheric dynamics Almost 221 hours of measurements have been collected by the lidars of the Maïdo Observatory between 11 and 19 May. A GRUAN exercise with multiple sondes flights (Vaisala, Modem and CFH) was performed during that campaign. After that

20 major campaign, the Lidar1200 was part of LIDEOLE-2. An 8-hours measurement session for the water vapor lidar was performed to test the optimal performances of the instrument on a long duration session. Within the scope of the evaluation of the performances of the lidar water vapor data, the dataset offered by those campaigns is exceptional, particularly the CFH dataset that will be part of the comparison.

\subsection{Presentation of the CFH soundings}

25 Various sondes are used in the world for the meteorological radiosoundings. With regard to relative humidity, it is recognized by many that the CFH sondes are among the most accurate especially in the UT/LS (Vömel et al., 2007). The CFH is a balloon borne hygrometer. The sensor is a chilled mirror with a cryogenic liquid. The principle of the hygrometer is based on the equilibrium between the saturation vapor pressure in the atmosphere and the water (or the ice) at the surface of the mirror at the dew (or frost) point (Oltmans and Hofmann, 1995; Vömel et al., 1995). The instrument adjusts the temperature of the

30 surface to maintain a slight layer of frost, this temperature is the frost or the dew point temperature of the air inside the sensor (Vömel et al., 2007) using the Goff-Gratch relationship, the water vapor mixing ratio can be then calculated. The uncertainty of the $\mathrm{CFH}$ sonde is lower than $4 \%$ in the lower tropical troposphere, lower than $9 \%$ in the area of the tropopause and around $10 \%$ in the middle atmosphere (around $28 \mathrm{~km}$; Vömel et al., 2007). For the best measurements, the mixing ratio uncertainty can even reach $1 \%$ in the lower troposphere and 2 to 3\% in the stratosphere (Vömel et al., 2016). The last WMO report (WMO,

35 2011) concluded that only the $\mathrm{CFH}$ sondes were able to measure the water vapor in the stratosphere comparing to the capacitive sensors radiosondes tested in 2010.

\subsection{Comparison methodology}

Six CFH sondes have been launched at the Maïdo Observatory during the MORGANE campaign. Among these sondes, one has been launched during the daytime and has not been included in the following comparisons. A methodology of comparison 

are compared to the 40-min sessions lidar data starting at the launch time of the balloon, except for the 15 May lidar data for which there is a shift of 11 minutes between the lidar session and the balloon launch due to delay in starting lidar operations. To compare the profiles in the UT/LS, the time integration for the lidar sessions needs to be expanded. Between 14 and $17 \mathrm{~km}$,

5 the relative difference was minimized if the whole night measurement session of the lidar is used. Above $17 \mathrm{~km}$, it is necessary to involve the whole campaign measurements to compare with the mean CFH profile of the campaign. On the other hand, the variability over the 15 days of the campaign seen by the $\mathrm{CFH}$ is less than 1 ppmv. Thus, the temporal variability of the water vapor at these altitudes allows to compare an individual profile with the lidar profile at the scale of the whole campaign. To sum up, in the following, the used Lidar1200 integration times are adjusted with respect to the analyzed tropospheric columns:

1040 minutes, night, and the whole campaign ( $\sim 48 \mathrm{~h}$ ) for the 2.2-14 km, 14-17 km and 17-22 km partial columns, respectively. These integration times/probed partial column pairs are established to maximize the lidar performances (vertical resolution, uncertainties) in these atmospheric layers following the considerations stated in Sect. 4.

\subsection{Results}

Figure 6 compares the Lidar1200 and CFH sondes mean water vapor mixing ratio profiles for the MORGANE campaign. On

15 the left, the mean $\mathrm{CFH}$ profile is superimposed on the lidar profile integrated over the whole campaign data in the lower stratosphere (Fig. 6A), and on the mean lidar profile of the 40-min sessions in the lower and middle troposphere (Fig. 6B) and of the night sessions in the upper troposphere (Fig. 6C). The relative difference between the lidar and CFH profiles is represented on Fig. 6a-c.

In the troposphere, the lidar data used for the comparison represents the average of the five 40-min coincident lidar

20 sessions, while the $\mathrm{CFH}$ data is the average of the $5 \mathrm{CFH}$ radiosoundings of the campaign. A good agreement is displayed in the troposphere (Fig. 6C and 6c). The mean relative difference for the $2.2-14 \mathrm{~km}$ partial column is about $9.5 \%$ and this is much smaller than the variability of the water vapor itself as seen by CFH (Fig. 6c). No positive or negative bias appears. All individual comparisons (not shown) agree similarly, except for the particular night of 19 May during which thin water vapor layers observed by the CFH sonde were different (in altitude or in amplitude) than those measured by the Lidar1200. This

25 explains why on Fig. $6 \mathrm{c}$ the relative difference is sometimes higher than $20 \%$ for few specific altitudes in the troposphere. The large spatio-temporal variability of the water vapor is our best-case scenario to explain large differences observed in this particular night that does not put into question either the quality of the measurement or the methodology of comparison. It just highlights the difficulty of optimizing the instrumental comparison. To conclude, the results for the comparison analysis in the troposphere (2.2-14 km) are good. In the upper troposphere (Fig. 6B and 6b), the lidar data used for the comparison represent

30 the average of the 5 night-sessions coincident with the $\mathrm{CFH}$ launches during the campaign. In the lower stratosphere (Fig.6A and 6a), the lidar data used for the comparison represent the integration of the whole 47-hours dataset of the campaign. Comparisons between lidar and CFH data are as good or better than expected in the 14-17 km layer, and they are especially good in the 17-22 km layer. The clearest evidence of this is to be found in the fact that the mean CFH profile is nearly always inside the error bar of the Lidar1200 profile (Fig. 6A and 6B). The mean relative difference between the mean CFH and

35 Lidar1200 profiles is $10.5 \%$ in the $14-17 \mathrm{~km}$ layer (Fig. 6b) and 7.5\% in the $17-22 \mathrm{~km}$ layer (Fig. 6a), which represents less than $1 \mathrm{ppm}$.

Below the tropopause (Fig. 6a and 6b), there is a positive bias on the mean lidar data which can be found also on the comparison with individual profiles. There is no obvious reason to explain this bias. It can be due to the reduced size of the available sample (5 CFH sondes). Above $22 \mathrm{~km}$ (not shown), the CFH and the Lidar1200 are not in agreement. According to

40 the CFH data of this campaign and despite the 47 hours of integration, the Lidar 1200 seems to be limited to $22 \mathrm{~km}$ asl, probably due to a smaller signal to noise ratio over this altitude and/or potential systematic uncertainties. More comparisons will be required to investigate further the reasons of this bias if its robustness is confirmed and the altitude of the upper limit for the 
Atmos. Meas. Tech. Discuss., doi:10.5194/amt-2017-32, 2017

\section{Atmospheric

Manuscript under review for journal Atmos. Meas. Tech.

Discussion started: 4 April 2017

(C) Author(s) 2017. CC-BY 3.0 License.

measurements.

To conclude, the Lidar1200 and the CFH profiles are in a good agreement in the whole region of the troposphere sampled by Lidar1200, and the MORGANE campaign profiles have been validated by the CFH sondes up to $22 \mathrm{~km}$ asl.

\section{Performances of the Lidar1200 in monitoring the water vapor}

5 The previous section has demonstrated the agreement between the reference instrument for tropospheric and stratospheric water vapor measurements (CFH) and the Lidar1200. The following section aims to provide an overview of the routine and optimal performances in terms of uncertainties, reachable altitude and vertical resolution.

\subsection{Mean performances}

To evaluate a mean uncertainty that might be associated to the Lidar1200 water vapor data regarding the altitude, three classes

10 of mean profiles have been calculated: all the 10,40 and 240 minutes unfiltered and uncalibrated measurements have been averaged. Those classes of profiles have been processed with the operating algorithm, associated uncertainties have been calculated and a suitable filter has been applied (21, 61 and 121 points, respectively). The uncertainty on the calibration coefficient equals to $2.7 \%$ (i.e. the standard mean calibration coefficient, Table 1). Figure 7 represents the different contributions of the uncertainties before filtering (on the left) and the total error (on the right) for each class of profile. As

15 introduced in Sect. 2.2.1, the total error is influenced by both the calibration and the statistical errors in the lowest troposphere and varies principally under the influence of the statistical error from the middle troposphere up to the lower stratosphere (Fig. 7). The uncertainty is largely influenced by the integration time and the filtering. Thus, it is important to use a suitable filter to find a good compromise between the vertical resolution and the total error (cf Sect. 4.4) for the latter not to be too large and not to hide the variability of the water vapor and the magnitude of the studied processes.

20 The total mean error for the average profiles of 10, 40 and 240 minutes reaches a threshold of $20 \%$ at around 11,14 and $16 \mathrm{~km}$ asl, respectively (Fig. 7). Those three classes of profiles provide information on the water vapor mixing ratio in the all troposphere and offer various time scales for studying atmospheric processes. At $14 \mathrm{~km}$ altitude, they present a total error of $75 \%, 23 \%$ and $6 \%$, respectively (Fig. 7). The 240-min class reaches the tropical tropopause between 25 and $30 \%$ of uncertainty. It appears to be important to reach the tropopause with a smaller uncertainty, and thus to integrate the

25 measurements for longer periods.

Estimating a mean error in the lower stratosphere is a challenging exercise. With nightly measurements, the stratosphere cannot be systematically reached with an uncertainty lower than $25 \%$, consequently longer integration time are required. One possibility consists in averaging lidar signal over several successive nights. Nevertheless, it is difficult to establish homogeneous measurement sessions with around ten hours of integration. If selecting randomly a period of 15 days,

30 except on a campaign mode, it will not be automatically possible for each period to reach 10 hours of measurements. Therefore, a more comprehensive strategy needs to be put in place. At present, the investigation of the variability of the water vapor in the UT/LS by lidar is limited to the use of monthly profiles as long as calibration coefficient can be considered as constant and long measurement session ( 8 hours) has been obtained during the one-month period. The Lidar1200 - and the Maïdo Observatory - being designed for long term operations, the goal here is to build up over decades a database containing monthly

35 UT/LS water vapor profiles. Such a database can be useful to make out climatology and long term trends of UT/LS hydration on this unique subtropical site.

Hoareau et al. (2012) estimated the performances of the Lidar1200 for the water vapor measurements based on numerical simulations. The results were that with 30 minutes of integration, the statistical error would be of $15 \%$ at $14.6 \mathrm{~km}$ and $30 \%$ at $16.3 \mathrm{~km}$ and that, with a sufficient number of data, the profiles could reach the stratosphere. The study of the 40-

40 minutes average profile of the November 2013 - October 2015 (before filtering) shows that for a statistical error of $15 \%$, the 
measurements would reach $9.7 \mathrm{~km}$ asl and $11.1 \mathrm{~km}$ asl for 30\% (Fig. 7). When looking at the total error (after filtering), it would be $15 \%$ at $13.1 \mathrm{~km}$ asl and of $30 \%$ at $14.2 \mathrm{~km}$ asl (Fig. 7). The simulation of performances of Hoareau et al. (2012) has been realized for a clear sky, without the moon and using two wavelengths (355 and $532 \mathrm{~nm}$ ). In practice, the Lidar1200 is operating with only one wavelength and for different moon phases. The mean profile here has been calculated on the whole

5 dataset without taking into account the moon or the cloud fraction effects. The measurement of water vapor of 9 hours of September 2015 showed that the moon phase has a non-negligible influence on the quality of the data (see Sect. 4.2). Based upon a situation corresponding to any night of measurements in routine (i.e. potentially submitted to the influence of the moon and variable meteorological conditions), the Lidar1200 shows, for a 240 -minutes integration time, a total error of $15 \%$ at 16.1 $\mathrm{km}$ and of $30 \%$ at $17.6 \mathrm{~km}$ (Fig. 7). Four hours of measurement are necessary to reach the upper troposphere.

\section{$10 \quad 4.2$ Optimal performances}

On a routine basis, 4 to 8 nights of measurements are obtained each month, typically of 1 to 4 hours in duration. Lidar measurements exceed 4-hours duration only on campaign mode. The campaigns at the Maïdo Observatory are an opportunity to evaluate the optimal performance of the Lidar1200. One of the main objectives during the campaigns (see Sect. 3.1) was to determine the maximum altitude range that could be reached when integrating several nights of measurements. Excluding

15 logistical issues associated with a manually operated lidar and assuming a clear sky night, the measurement session would exceed ten hours. A test has been realized during the LIDEOLE-2 campaign with a night session of about 9 hours. The profile of 24 September 2015 integrated on the all-night measurements reaches approximately 18 to $19 \mathrm{~km}$ altitude with an uncertainty of the order of magnitude of 35\% (4-5 ppmv, Fig. 8). The sky was clear but the measurements were not optimal all the nightlong, because between 15:00 and 17:00 UTC the full moon was not favorable to the measurement due to increased background.

20 Between the beginning and the end of the measurement, the sky background increased by 100 times on the $387 \mathrm{~nm}$ channel and by 10 times on the $407 \mathrm{~nm}$ channel. The increase in background affects the first two hours of measurements, which limits those profiles to a maximum altitude of $14 \mathrm{~km}$. Despite this limiting, the all-night profile is able to give information on the water vapor up to the tropopause, and lower stratosphere. The factors preventing the realization of a 10-hours measurement night are various and make this kind of test difficult to put into place on a routine basis.

Ten hours of integration represent the minimum measure until $18 \mathrm{~km}$ with a relative error around $30 \%$. The different campaigns allowed us to evaluate the performance of the Lidar1200 in the lower stratosphere in the range of 18-22 km. The characteristics of the profiles obtained during the campaigns (Fig. 9) are summarized in Table 2. The upper limit is the altitude where the lidar uncertainty corresponds to twice the variability of the water vapor in the lower stratosphere. It is noteworthy that the monthly (and even shorter) water vapor variability in the lower stratosphere needs to be further investigated and remain

30 a scientific issue. Two values of variability have been empirically chosen to illustrate the optimal performance of the Lidar1200. Regarding a 0.5 ppmv water variability (i.e. 1 ppmv absolute error), the upper altitude corresponding to the above definition would be $16 \mathrm{~km}$ asl, $17.5 \mathrm{~km}$ asl and $16.5 \mathrm{~km}$ asl for 12, 24 and 32 hours of integration, respectively (Fig. 10). Regarding a 1-ppmv water variability (i.e. 2 ppmv absolute error), the upper altitude corresponding to the above definition would be $18.5 \mathrm{~km}$ asl, $20 \mathrm{~km}$ asl and $19.1 \mathrm{~km}$ asl for 12, 24 and 32 hours of integration, respectively (Fig. 10; Table 2). The

35 relative error for this altitude varies between $15 \%$ and $22 \%$ and between 24 and $31 \%$ for 0.5 and 1 ppmv lower stratospheric water vapor variability, respectively (Table 2). By doubling or tripling the integration time, the mean profile reaches $600 \mathrm{~m}$ to $1.4 \mathrm{~km}$ higher with a relative error of about $30 \%$ (Table 2). At these altitudes, the vertical resolution is $1.3 \mathrm{~km}$. An integration time which allows altitudes several kilometers above the tropopause to be reached, has only been possible during the MORGANE campaign, and required about 50 hours of measurements. In this case, the uncertainty in the stratosphere varies 40 between 6 and $18 \%$ (at 17 and $22 \mathrm{~km}$ asl, respectively, Fig. 10).

Theses campaign profiles highlight the capacity of the lidar of retrieving information in the lower stratosphere with a quantified competitive error. Nevertheless, even if the water vapor can be measured at $18 \mathrm{~km}$ for around ten hours, the relative 
error is important: $33 \%$ for the 9-hours profiles (Fig. 8). When extending significantly the duration of the integration time, this uncertainty is of $26 \%$ for $32 \mathrm{~h}$ (Fig. 10), while 50 hours are necessary to decrease the uncertainty to $9 \%$ (Fig. 10). When the duration of the integration time is substantial, the measurement can be very accurate with an absolute error lower than $1 \mathrm{ppmv}$ between the tropopause and $22 \mathrm{~km}$. The intensive observation periods during the campaigns allow us to get more accurate

5 mean results; the stationary character of the water vapor content of air masses is maximized regarding the long-term variability of the water vapor above $18 \mathrm{~km}$. The campaigns were organized in spring and autumn, it would be beneficial to have future campaigns in the winter and summer seasons.

The calculation of the standardized error on calibration leads to a small value. The performances based on the mean profiles are shown to be good in the troposphere. The CFH water vapor profiles during the MORGANE campaign demonstrate

10 the accuracy of the Lidar1200 in the UT/LS (see Sect. 3.4). Between the tropopause and $22 \mathrm{~km}$, the evaluation of the performances highlights the accuracy of the Lidar1200 measurement with a consequent time of integration and with an absolute error less than 1 ppmv. The work of evaluation of the performances and validation of profiles validates the criteria of the measurement integration (described in the Sect. 4.4) with respect to altitude or the process studied (Table 3). The performances of the instrument have been defined and the data are validated, so the database can be used by the scientific community.

\section{4.3 Detection and monitoring of fine scale structures in the troposphere}

One of the key points about the Lidar1200 is its capacity to detect and monitor water vapor structures. Such structures may be signatures of transport and dynamical processes that might be interesting to study in the tropical UT/LS. It is a challenge for the Lidar1200 to be able to retrieve profiles with a high resolution because such structures might be very thin, i.e. around a few hundred of meters, with a short lifetime.

Before the MORGANE campaign, a first CFH sonde has been launched from the Maïdo Observatory on 18 November 2014. This dataset was not included in the previous validation test because both $\mathrm{CFH}$ and lidar profiles were not valid in the upper troposphere. Nevertheless, the comparison of the water vapor mixing ratio profiles on 18 November 2014 shows a good agreement in the troposphere (Fig. 11) and captures an interesting event in relation to the detection of fine-scale structures. The 120-min session lidar profile does not detect the water vapor mixing ratio thin minimum (500 $\mathrm{m}$ thickness) included in

25 the thicker wet layer between 8.8 and $10.3 \mathrm{~km}$ (Fig. 11 top). Nevertheless, if the lidar data are integrated on only 40- or 30minutes sessions, the minimum is detected (Fig. 11 bottom). It means that fine structures can be smoothed by the data processing if the integration time is not adapted to the lifetime of the processes.

Another comparison has been performed on 18 May 2015. A peak of water vapor mixing ratio is located at $9 \mathrm{~km}$ asl, with a thickness of $100 \mathrm{~m}$, at 17:35 UTC as observed by a CFH sonde (Fig. 12, black line). This peak is rather poorly reproduced

30 with the 40-min session lidar data (Fig. 12, red line), while, on the contrary, it is better detected and reproduced with 10-min session lidar data (Fig. 12). At 17:10 UTC, the lidar already detects a thin wet layer of $400 \mathrm{~m}$ and a maximum of $133 \mathrm{ppmv}$ at $9.05 \mathrm{~km}$ (Fig. 12, in yellow). This layer is monitored $100 \mathrm{~m}$ further down 10 minutes later, then becomes thinner, gets wetter until shaping the peak observed by the CFH between 17:20 and 17:30 (Fig. 12, in green). Magnitudes of the peak are very similar, 158 ppmv by the lidar versus 180 ppmv by the CFH. The CFH dataset does not give any information of what the

35 structure becomes, alternatively the lidar dataset shows that this peak stays at the same altitude with the same thickness and gets drier (Fig. 12, in cyan), dries further, then disappears (Fig. 12, blue curve). It is an example of the opportunity of fine scale monitoring of atmospheric structures that the Lidar1200 may provide for geophysical studies.

\subsection{Summary}

The benefit of the hindsight on the 2-years dataset allowed us to define empirically a user's guide for the time integration of 40 the data leading to a good compromise between the uncertainty and the vertical resolution (Table 3). The detection of finescale structures (vertical thickness of a few hundreds of meters) might be realized with 10-minutes integration files. To realize 

necessary. To reach the troposphere above $14 \mathrm{~km}$ asl, the time integration should cover at least 4 hours. Around 10-hours of integration are required to reach altitudes above the tropopause and a coarse vertical resolution is implied as a consequence. Depending on the scientific investigations, specific filter points and integration times are chosen (Table 3). The vertical

5 resolution is coarser in the lower stratosphere but does not exceed $1.3 \mathrm{~km}$. The vertical resolution is the finest for profiles of few minutes (with a number of points of the filter reaching 21) and is greater than $100 \mathrm{~m}$ (Fig. 1).

\section{Overview of the database and preliminary characterization of seasonal variations of water vapor}

\subsection{Presentation of the 2-years water vapor database}

The 2-years validated water vapor dataset extends from November 2013 to October 2015 (note that the measurements

10 made during the test phase, October 2012 - October 2013, are internally used for specific technical studies). The functioning of the instrument became more stable on the period from November 2013 on. The number of nights of measurement has increased from 66 to 84 nights per year. The number of hours of operation increased almost $60 \%$ year-over-year from $185 \mathrm{~h}$ during November 2013 - October 2014 to 293 h during November 2014 - October 2015. There was an average of 1 to 2 measurement nights per week. This dataset includes the routine measurement periods but also Intensive Observing Periods

15 (IOP) during campaigns described in Sect. 3.1. Efforts in increasing the number of measurement sessions on top of IOPs during campaigns ensured that $40 \%$ of the measurement periods in the second year were greater or equal to $240 \mathrm{~min}$. The ratio of 120-240 min sessions compared to $>240$ min sessions, respectively $44 \%$ and $36 \%$ to the whole dataset (Fig. 13), and the most frequent measurements sessions around $240 \mathrm{~min}$ shows that the time slot of routine operations (i.e. around 19:00 to 01:00+1 LT) is well covered. The measurements are subject to instrumental problems and depend on the availability of the technical

20 staff and, in addition, to meteorological conditions (clear sky nights only). Summer (DJF) is the rainy season and the least number of measurements occur (Fig. 14). The frequencies of measurements for the three other seasons are in close proportions (Fig. 14), even if it should be noted that statistics for the MAM and SON periods are boosted by the campaigns in November 2013, June 2014 (non-official short campaign), November 2014, and May and September 2015.

\subsection{First Maïdo tropospheric seasonal variations of water vapor mixing ratio}

25 A methodology has been put into place to measure monthly profiles of water vapor mixing ratio. It consists of generating monthly lidar profiles with sessions of 8-hours up to 48-hours with a calibration assumed to be unchanged. Above $80 \%$ of error, data are not taken. These monthly profiles reach the UT with an acceptable uncertainty (less than 10\%). Figure 15 is the first-time series of monthly water vapor profiles of the Lidar1200 over the 2-years database. In spite of the difficulty of the lack of data in January and August, the water vapor seasonal cycle is well documented with the peak of the wet (dry) season

30 in DJF (JJA), which clearly offers hope to further investigating of inter-annual variability and trends with an extended coverage of the database.

Hoareau et al. (2012) had analyzed the profiles obtained between 2002 and 2005 by the instrument in operation in Saint-Denis, before its upgrading and transfer to the Maïdo Observatory, and found a water vapor seasonal cycle from the ground to $9 \mathrm{~km}$ characterized by a ratio (wet seasonal mixing ratio/dry season mixing ratio) between 0.5 and 3 . No seasonal

35 cycle was found between 9 and $15 \mathrm{~km}$. The analysis of the new dataset at Maïdo in 2013-2015 confirms a clear seasonal cycle in the lower and middle troposphere. In addition, values in the TTL (Tropical Tropopause Layer) and in the lower stratosphere show some variability, but no seasonal cycle. However, two differences are found:

1. The seasonal cycle is observed higher in the troposphere compared to Hoareau et al. (2012). Figure 15 shows a clear seasonal variation until $13 \mathrm{~km}$, as opposed to $9 \mathrm{~km}$.

40 2. Typical monthly values during wet season are 5000, 600 and $15 \mathrm{ppmv}$ at 5, 10 and $15 \mathrm{~km}$ respectively. During the 
dry season, typical values are 400,40 and 10 ppmv for the same altitudes.

If we apply the same methodology than Hoareau et al. (2012) and calculate a ratio between the monthly values during wet and dry seasons, we find values for this ratio between 5 and 10, significantly larger than ratios found by Hoareau et al. (2012). That indicates that the improved technical performance of the system and progresses in data processing and especially in the

5 calibration methodology allow us to better establish the seasonal cycle of water vapor, in terms of difference between dry and wet season, and on the vertical range. Future works will be devoted to better characterize the water vapor variability and associated processes, and long term trends.

Among interesting features of this seasonal cycle, Figure 15 shows the great importance of the lowest layer content regarding the total column of water vapor whatever the season, the descent of very dry air below $4 \mathrm{~km}$ altitude in JJA, and the

10 occurrence of a relative maxima of water vapor mixing ratio above the tropopause (e.g. October 2014, June-July 2015).

\section{Conclusions}

The spatio-temporal variability of the water vapor is not well documented through direct observations. To improve its understanding, it is necessary to establish climatologies and trends at global and regional scales in the troposphere and in the stratosphere, to characterize the fine scale structures and to document the associated atmospheric processes. The difficulty in

15 performing these investigations can be found in collecting homogeneous water vapor observations covering the entire atmospheric column (i.e. up to the UT/LS) with an acceptable error. These data should be obtained regularly over decades with a vertical resolution sufficient to discern the major dynamical processes, and extend to the UT/LS. The establishment of such a dataset on several sites worldwide is an important priority for the international networks such as NDACC and GRUAN. These networks require stable instrumental systems supplying data with a high accuracy, the characterization of the sources of

20 uncertainty, and well documented data processing. Such efforts have been deployed here to produce water vapor profiles using the Lidar1200. In operation at the Maïdo Observatory (Reunion Island) since 2013, this instrument delivered its first two years of data. The different steps of the process of evaluation of the performances of the Lidar1200 that have been realized as follows.

- The establishment of a calibration methodology based on GNSS IWV for a long-term stable data processing has been made.

25 At the Maïdo Observatory, the GNSS technique is successfully used on a routine basis. A methodology based on the identification of quasi-stationary period of the hourly calibration coefficients has been applied and tested on the 2013-2015 dataset, allowing a robust calibration of the Lidar1200. The average standard error on the calibration coefficient is $2.7 \%$ illustrating the efficiency of this method. This is the first time, to our knowledge, that a Raman water vapor lidar is demonstrated to be successfully calibrated through GNSS IWV measurements on a routine basis.

- The comparison between the CFH sondes launched during MORGANE and the lidar profiles led to the conclusion that the performance of the Lidar1200 is nominal in the whole troposphere.

The relative difference between both techniques is less than the water vapor variability in the troposphere during this period. In the UT and in the LS, the absolute difference is lower than 0.8 ppmv. With respect to the CFH and lidar uncertainties, the instruments are in agreement up to the UT/LS and the CFH profiles validated the lidar data up to $22 \mathrm{~km}$ asl. This agreement

35 between the Lidar1200 and the CFH validates the methodology of calibration of the Lidar1200 and the data processing scheme.

- The sources of error have been identified and quantified, and the optimal Lidar1200 performance has been evaluated. The statistical error exponentially increases with the altitude and dominates in the UT/LS. The Lidar1200 mean profiles of 10, 40 and 240 minutes illustrate the total uncertainties that can be achieved in the troposphere. Layers with thicknesses of a few

40 hundred of meters can be detected with a temporal resolution of 10 minutes up to around $10 \mathrm{~km}$ asl. The 240 -minutes average profile reaches $16 \mathrm{~km}$ asl for a total error of $20 \%$, i.e. a night measurements should retrieve information up to the upper 

of data is needed to cross the tropopause. Increasing the range of one kilometer in the lower stratosphere requires another 10 to 20 more hours in the integration time. The total integration time of 47 hours of the MORGANE campaign allowed measurements to reach $22 \mathrm{~km}$ asl with an absolute error less than $0.8 \mathrm{ppmv}$, a relative error lower than $20 \%$ and a vertical

5 resolution of $1.3 \mathrm{~km}$. This work of evaluation led to the creation of a user's guide: the definition of criteria of integration times and filtering adjusted to the process studied in terms of altitude, thickness and temporal scale.

Some preliminary results have been obtained from analyzing the new dataset at Maïdo in 2013-2015. This analysis confirms a clear seasonal cycle in the lower and middle troposphere. In addition, values in the TTL and in the lower stratosphere show some variability, but no seasonal cycle. Some differences with a climatology established by a previous instrument

10 configuration in operation at Saint-Denis in 2002-2005 (Hoareau et al., 2012) have been evidenced, in relation to the vertical range where a seasonality can be observed, and to the amplitude of the difference between dry and wet season.

To conclude, the Lidar1200 meets the instrumental specifications, it was designed for: providing water vapor profiles with high vertical and temporal resolution in the troposphere on a routine basis and able to detect in the lower tropical stratosphere quantities of water vapor of only a few ppmv. The design of the instrument, the excellent environment of 15 measurement offered by the Maïdo Observatory, the robustness of the calibration methodology, the transparency on the data processing algorithm, the quantification of the total error and the instrumental comparison certify the willingness of the Lidar1200 team to respond to the definition of "a reference observation" suggested by Immler et al. (2010). As a matter of fact, the water vapor Lidar1200 NDACC application based on the results shown here has recently been positively reviewed by the NDACC steering committee. The Lidar 1200 is now able to provide international networks with various routine water vapor

20 data profiles Level 2 products (Table 4), whose use and relevance depend on the user's scientific objectives. This regular instrumental comparison effort is secured through the recurrent CFH soundings performed at the Maïdo Observatory in the GRUAN framework. Aside from its quality, the exceptional character of this dataset resides in its location in the Southern Hemisphere, subject to dynamical processes associated to tropical and subtropical areas. The data of the Lidar1200 on their own or with others measurements performed in Reunion Island bring or will bring new results on the characterization of the

25 water vapor in the troposphere, the monitoring of the water vapor in the UT/LS, the study of the exchanges processes between the stratosphere and the troposphere and the validation of satellites measurements.

Acknowledgments. The lidar data used in this publication were obtained as part of the Network for the Detection of Atmospheric Composition Change (NDACC) and level 2 product as daily vertical water vapor profiles will be publicly

30 available through the NDACC portal (http://www.ndacc.org) and the French atmospheric data portal (http://www.poleether.fr/). Raw data and other products will be available on demand and available at the OPAR web portal.

We acknowledge the ACTRIS project and support of the European Community (Research Infrastructure Action under the FP7 "Capacities" specific program for Integrating Activities, ACTRIS Grant Agreement no. 262254). Acknowledgements are addressed to the European Commission (FEDER program), Région Réunion and CNRS for their strong support in the

35 building of the Maïdo facility. Acknowledgements are also addressed to the Université de La Réunion and CNRS for their strong support of the OPAR station (Observatoire de Physique de l'Atmosphère de La Réunion, UMR8105, UMR8190 and UMS3365) and the OSU-R activities. The authors gratefully acknowledge E. Golubic, P. Hernandez and L. Mottet who are deeply involved in the routine lidar observations at OPAR.

The research leading to these results was supported by the LEFE INSU-CNRS French Program under the projects

40 VAPEURDO and VEGA. Thanks to CNRS (Centre National de Recherche Scientifique/France) and the University of Reunion Island for funding the $\mathrm{PhD}$ of $\mathrm{H}$. Vérèmes and the MALICCA campaigns.

Thanks to Yann Courcoux, to Jacques Porteneuve and to Alain Hauchecorne. Thanks to Davide Dionisi for his work on the water vapor data processing. 
Atmos. Meas. Tech. Discuss., doi:10.5194/amt-2017-32, 2017

Atmospheric

Manuscript under review for journal Atmos. Meas. Tech.

Discussion started: 4 April 2017

(c) Author(s) 2017. CC-BY 3.0 License.

\section{References}

Argall, P. S., Sica, R. J., Bryant, C. R., Algara-Siller, M., and Schijns, H.: Calibration of the Purple Crow Lidar vibrational Raman water-vapour mixing ratio and temperature measurements, Can. J. Phys., vol. 85, no. 2, 119-129, 2007.

Baray, J.-L., Courcoux, Y., Keckhut, P., Portafaix, T., Tulet, P., Cammas, J.-P., Hauchecorne, A., Godin-Beekmann, S.,

5 De Mazière, M., Hermans, C., Desmet, F., Sellegri, K., Colomb, A., Ramonet., M., Sciare, J., Vuillemin, C., Hoareau, C., Dionisi, D., Duflot, V., Vérèmes, H., Porteneuve, J., Gabarrot, F., Gaudo, T., Metzger, J.-M., Payen, G., Leclair de Bellevue, J., Barthe, C., Posny, F., Ricaud, P., Abchiche, A., and Delmas, R.: Maïdo observatory: a new high-altitude station facility at Reunion Island $\left(21^{\circ} \mathrm{S}, 55^{\circ} \mathrm{E}\right)$ for long-term atmospheric remote sensing and in-situ measurements, Atmos. Meas. Tech., 6 , 2865-2877, 2013.

10 Barnes, J. E., Kaplan, T., Vömel, H., and Read, W. G.: NASA/Aura/Microwave Limb Sounder water vapor validation at Mauna Loa Observatory by Raman lidar, J. Geophys. Res., vol. 113, no. D15, D15S03, 2008.

Bevis, M., Businger, S., Herring, T. A., Rocken, C., Anthes, R. A., and Ware R. H.: GPS meteorology: Remote sensing of atmospheric water vapor using the global positioning system, J. Geophys. Res., vol. 97, no. D14, 15787-15801, 1992.

Bock, O., Bosser, P., Bourcy, T., David, L., Goutail, F., Hoareau, C., Keckhut, P., Legain, D., Pazmino, A., Pelon, J., Pipis,

15 K., Poujol, G., Sarkissian, A., Thom, C., Tournois, G., and Tzanos, D.: Accuracy assessment of water vapour measurements from in situ and remote sensing techniques during the DEMEVAP 2011 campaign at OHP, Atmos. Meas. Tech., vol. 6, no. 10, 2777-2802, 2013.

Bock, O., Bosser, P., Pacione, R., Nuret, M., Fourrié, N., and Parracho, A.: A high-quality reprocessed ground-based GPS dataset for atmospheric process studies, radiosonde and model evaluation, and reanalysis of HyMeX Special Observing Period,

20 Q.J.R. Meteorol. Soc., vol. 142, 56-71, 2016.

Bodeker, G., Bojinski, S., Cimini, D., Dirksen, R., Haeffelin, M., Hannigan, J., Hurst, D., Leblanc, T., Madonna, F., Maturilli, F., Mikalsen, A., Philipona, R., Reale, T., Seidel, D., Tan, D., Thorne, P., Vömel, H., and Wang, J.: Reference upper-air observations for climate: From concept to reality. Bull. Amer. Meteor. Soc., doi:10.1175/BAMS-D-14-00072.1, 2015.

Bojinski, S., Verstraete, M., Peterson, T. C., Richter, C., Simmons, A., and Zemp, M.: The Concept of Essential Climate

25 Variables in Support of Climate Research, Applications, and Policy, Bull. Amer. Meteor. Soc., vol. 95, no. 9, 1431-1443, 2014.

Dionisi, D., Congeduti, F., Liberti, G. L., and Cardillo, F.: Calibration of a Multichannel Water Vapor Raman Lidar through Noncollocated Operational Soundings: Optimization and Characterization of Accuracy and Variability, J. Atmos. Ocean. Tech., vol. 27, no. 1, 2010.

30 Dionisi, D., Keckhut, P., Courcoux, Y., Hauchecorne, A., Porteneuve, J., Baray, J.-L., Leclair de Bellevue J., Vérèmes, H., Gabarrot, F., Decoupes, R., and Cammas, J.-P.: Water vapor observations up to the lower stratosphere through the Raman lidar during the Maïdo LIdar Calibration Campaign, Atmos. Meas. Tech., 8, 1425-1445, 2015.

Emardson, T. R. and H. J. P. Derks : On the relation between the wet delay and the integrated precipitable water vapour in the European atmosphere, Met. Apps, vol. 7, no. 1, 61-68, 2000.

35 Foelsche, U. and Kirchengast, G.: Tropospheric water vapor imaging by combination of ground-based and spaceborne GNSS sounding data, J. Geophys. Res., vol. 106, no. D21, 27221-27231, 2001.

Foth, A., Baars, H., Di Girolamo, P., and Pospichal, B.: Water vapour profiles from Raman lidar automatically calibrated by microwave radiometer data during HOPE, Atmos. Chem. Phys., vol. 15, no. 14, 7753-7763, 2015.

GCOS: The second report on the adequacy of the Global Observing Systems for Climate in support of the UNFCCC, GCOS-

40 82, WMO Tech. Doc. 1143, 85 pages, 2003.

Hoareau, C., Keckhut, P., Baray, J.-L., Robert, L., Courcoux, Y., Porteneuve, J., Vömel, H., and Morel, B.: A Raman lidar at La Reunion $\left(20.8^{\circ} \mathrm{S}, 55.5^{\circ} \mathrm{E}\right)$ for monitoring water vapour and cirrus distributions in the subtropical upper troposphere: preliminary analyses and description of a future system, Atmos. Meas. Tech., vol. 5, no. 6, pp. 1333-1348, 2012. 
Atmos. Meas. Tech. Discuss., doi:10.5194/amt-2017-32, 2017

Atmospheric

Manuscript under review for journal Atmos. Meas. Tech.

Discussion started: 4 April 2017

(c) Author(s) 2017. CC-BY 3.0 License.

Immler, F. J., Dykema, J., Gardiner, T., Whiteman, D. N., Thorne, P. W., and Vömel, H.: Reference Quality Upper-Air Measurements: guidance for developing GRUAN data products, Atmos. Meas. Tech., vol. 3, no. 5, 1217-1231, 2010.

Keckhut, P., Courcoux, Y., Baray, J.-L., Porteneuve, J., Vérèmes, H., Hauchecorne, A., Dionisi, D., Posny, F., Cammas, J.-P., Payen, G., Gabarrot, F., Evan, S., Khaykin, S., Rüfenacht, R., Tschanz, B., Kämpfer, N., Ricaud, P., Abchiche, A., Leclair-de-

5 Bellevue, J., and Duflot, V.: Introduction to the Maïdo Lidar Calibration Campaign dedicated to the validation of upper air meteorological parameters, J. Appl. Remote Sens, vol. 9, no. 1, 094099-094099, 2015.

Kennett, E. J. and Toumi, R.: Temperature dependence of atmospheric moisture lifetime, Geophys. Res. Lett., vol. 32, no. 19, L19806, 2005.

King, R.W. and Y. Bock, Y.: Documentation for the GAMIT analysis software, release 10.32, Massachusetts Institute of

10 Technology, Cambridge, USA, 2007.

Kurylo, M. J. and Solomon, S.: Network for the Detection of Stratospheric Change : a status and implementation report, Issued by NASA Upper Atmosphere Research Program and NOAA Climate and Global Change Program, 70 pages, 1990.

Läderach, A. and Sodemann, H.: A revised picture of the atmospheric moisture residence time, Geophys. Res. Lett., 2015GL067449, 2016.

15 Leblanc, T., McDermid, I. S., and Walsh, T. D.: Ground-based water vapor raman lidar measurements up to the upper troposphere and lower stratosphere for long-term monitoring, Atmos. Meas. Tech., vol. 5, no. 1, 17-36, 2012.

Leblanc, T., Sica, R. J., van Gijsel, J. A. E., Godin-Beekmann, S., Haefele, A., Trickl, T., Payen, G., and Gabarrot, F.: Proposed standardized definitions for vertical resolution and uncertainty in the NDACC lidar ozone and temperature algorithms - Part 1: Vertical resolution, Atmos. Meas. Tech., vol. 9, no. 8, 4029-4049, 2016.

20 Livesey, N. J., Read, W. G., Froidevaux, L., Lambert, A., Manney, G. L., Pumphrey, H. C., Santee, M. L., Schwartz, M. J., Wang, S., Cofield, R. E., Cuddy, D. T., Fuller, R. A., Jarnot, R. F., Jiang, J. H., Knosp, JB. W., Stek, P. C., Wagner, P. A., and Wu, D. L.: EOS MLS Version 3.3 Level 2 data quality and description document, Tech. rep., Jet Propulsion Laboratory, available from http://mls.jpl.nasa.gov/, 2011.

McGee, T. J., Whiteman, D. N., Ferrare, R. A., Butler, J. J., and Burris, J. F.: STROZ LITE: Stratospheric Ozone Lidar Trailer

25 Experiment, Opt. Eng, vol. 30, no. 1, 31-39, 1991.

Miloshevich, L. M., Vömel, H., Whiteman, D. N., Lesht, B. M., Schmidlin, F. J., and Russo, F.: Absolute accuracy of water vapor measurements from six operational radiosonde types launched during AWEX-G and implications for AIRS validation, J. Geophys. Res., vol. 111, no. D9, D09S10, 2006.

Niell, A. E., Coster, A. J., Solheim, F. S., Mendes, V. B., Toor, P. C., Langley, R. B., and Upham, C. A.: Comparison of

30 Measurements of Atmospheric Wet Delay by Radiosonde, Water Vapor Radiometer, GPS, and VLBI, J. Atmos. Oceanic Technol., vol. 18, no. 6, 830-850, 2001.

Oltmans, S. J. and Hofmann, D. J.: Increase in lower-stratospheric water vapour at a mid-latitude Northern Hemisphere site from 1981 to 1994, Nature, vol. 374, no. 6518, 146-149, 1995.

Read, W. G., Lambert, A., Bacmeister, J., Cofield, R. E., Christensen, L. E., Cuddy, D. T., Daffer, W. H., Drouin, B. J., Fetzer,

35 E., Froidevaux, L., Fuller, R., Herman, R., Jarnot, R. F., Jiang, J. H., Jiang, Y. B., Kelly, K., Knosp, B. W., Kovalenko, L. J., Livesey, N. J., Liu, H.-C., Manney, G. L., Pickett, H. M., Pumphrey, H. C., Rosenlof, K. H., Sabounchi, X., Santee, M. L., Schwartz, M. J., Snyder, W. V., Stek, P. C., Su, H., Takacs, L. L., Thurstans, R. P., Vömel, H., Wagner, P. A., Waters, J. W., Webster, C. R., Weinstock, E. M., and Wu, D. L. : Aura Microwave Limb Sounder upper tropospheric and lower stratospheric $\mathrm{H} 2 \mathrm{O}$ and relative humidity with respect to ice validation, J. Geophys. Res., vol. 112, no. D24, D24S35, 2007.

40 Saastamoinen, J.: Atmospheric Correction for the Troposphere and Stratosphere in Radio Ranging Satellites, in The Use of Artificial Satellites for Geodesy, S. W. Henriksen, Armandoncini, and B. H. Chovitz, Eds. American Geophysical Union, 247$251,1972$.

Seidel, D. J., Berger, F. H., Immler, F., Sommer, M., Vömel, H., Diamond, H. J., Dykema, J., Goodrich, D., Murray, W., 
Atmos. Meas. Tech. Discuss., doi:10.5194/amt-2017-32, 2017

\section{Atmospheric

Manuscript under review for journal Atmos. Meas. Tech.

Discussion started: 4 April 2017

(C) Author(s) 2017. CC-BY 3.0 License.

Peterson, T., Sisterson, D., Thorne, P., and Wang, J.: Reference Upper-Air Observations for Climate: Rationale, Progress, and Plans, Bull. Amer. Meteor. Soc., vol. 90, no. 3, 361-369, 2009.

Sherlock, V., Hauchecorne, A., and Lenoble, J.: Methodology for the Independent Calibration of Raman Backscatter WaterVapor Lidar Systems, Applied Optics, vol. 38, no. 27, 5816, 1999a.

5 Sherlock, V., Garnier, A., Hauchecorne, A., and Keckhut, P.: Implementation and Validation of a Raman Lidar Measurement of Middle and Upper Tropospheric Water Vapor, Applied Optics, vol. 38, no. 27, 5838, 1999b.

Solomon, S., Rosenlof, K., Portmann, R., Daniel, J., Davis, S., Sanford, T., and Plattner, G.-K.: Contributions of stratospheric water vapor to decadal changes in the rate of global warming, Science, 327, 1219-1223, 2010.

Sullivan, J. T., McGee, T. J., Sumnicht, G. K., Twigg, L. W., and Hoff, R. M.: A mobile differential absorption lidar to measure

10 sub-hourly fluctuation of tropospheric ozone profiles in the Baltimore-Washington, D.C. region, Atmos. Meas. Tech., vol. 7, no. 10, 3529-3548, 2014.

Trenberth, K. E.: Atmospheric Moisture Residence Times and Cycling: Implications for Rainfall Rates and Climate Change, Climatic Change, vol. 39, no. 4, 667-694, 1998.

Turner, D. D., Linne, H., Bosenberg, J., Lehmann, S., Ertel, K., Goldsmith, J. E. M., and Tooman, T. P.: Simultaneous ground-

15 based remote sensing of water vapor by differential absorption and Raman lidars, in Geoscience and Remote Sensing Symposium, 2000. Proceedings. IGARSS 2000. IEEE 2000 International, 2000, vol. 4, pp. 1455-1458 vol.4, 2000.

Vogelmann, H., Sussmann, R., Trickl, T., and Borsdorff, T.: Intercomparison of atmospheric water vapor soundings from the differential absorption lidar (DIAL) and the solar FTIR system on Mt. Zugspitze, Atmos. Meas. Tech., vol. 4, no. 5, 835-841, 2011.

20 Vogelmann, H., Sussmann, R., Trickl, T., and Reichert, A.: Spatiotemporal variability of water vapor investigated using lidar and FTIR vertical soundings above the Zugspitze, Atmos. Chem. Phys., vol. 15, no. 6, 3135-3148, 2015.

Vömel, H., Oltmans, S. J., Hofmann, D. J., Deshler, T., and Rosen, J. M.: The evolution of the dehydration in the Antarctic stratospheric vortex, J. Geophys. Res., vol. 100, no. D7, 13919-13926, 1995.

Vömel, H., David, D. E., and Smith, K.: Accuracy of tropospheric and stratospheric water vapor measurements by the

25 cryogenic frost point hygrometer: Instrumental details and observations, J. Geophys. Res., vol. 112, no. D8, D08305, 2007.

Vömel, H., Naebert, T., Dirksen, R., and Sommer, M.: An update on the uncertainties of water vapor measurements using cryogenic frost point hygrometers, Atmos. Meas. Tech., vol. 9, no. 8, 3755-3768, 2016.

Wandiger, U.: Raman lidar, in: Weitkamp C., ed., LIDAR: Range-Resolved Optical Remote Sensing of the Atmosphere. Springer, Berlin, p. 241-271, 2005.

30 WMO report by Nash, J., Oakley, T., Vömel, H., Wei, Li.: WMO intercomparison of high quality radiosonde systems, Yangjiang, China, 12 July-3 August 2010, WMO Instruments and Observing Methods. Report No. 107, 2011.

Wulfmeyer, V., Hardesty, R. M., Turner, D. D., Behrendt, A., Cadeddu, M. P., Di Girolamo, P., Schlüssel, P., Van Baelen, J., and Zus, F.: A review of the remote sensing of lower tropospheric thermodynamic profiles and its indispensable role for the understanding and the simulation of water and energy cycles, Rev. Geophys., vol. 53, no. 3, p. 2014RG000476, 2015. 
Atmos. Meas. Tech. Discuss., doi:10.5194/amt-2017-32, 2017

Manuscript under review for journal Atmos. Meas. Tech.

Discussion started: 4 April 2017

(c) Author(s) 2017. CC-BY 3.0 License.

\section{(c) (i)}

5

10

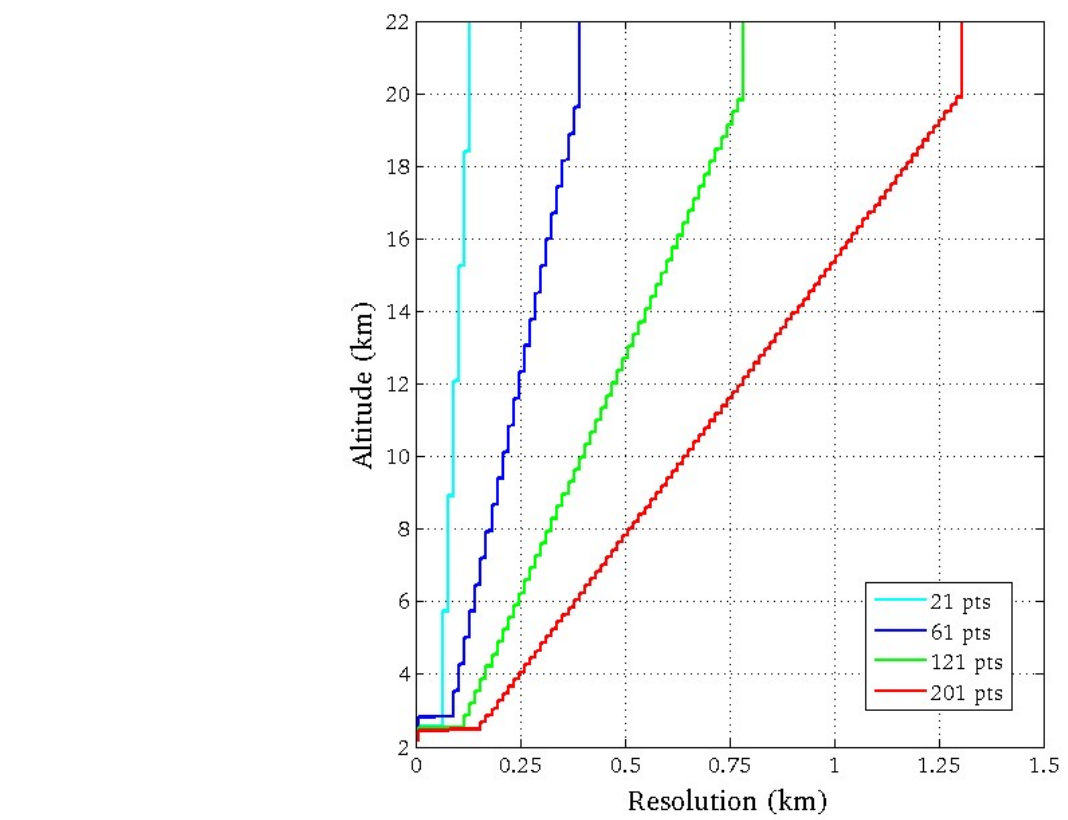

15
Atmospheric Measurement

Techniques

Discussions

20 Figure 1. Vertical resolution of the Lidar1200 profile versus altitude ( $\mathrm{km}$ asl) with respect to the number of points of the filter (Blackman coefficients): 21 points in blue, 61 in cyan, 121 in green and 201 points in red, at the altitude of $20 \mathrm{~km}$ asl. 
Atmos. Meas. Tech. Discuss., doi:10.5194/amt-2017-32, 2017

Manuscript under review for journal Atmos. Meas. Tech.

Discussion started: 4 April 2017

(c) Author(s) 2017. CC-BY 3.0 License.

$\begin{array}{r}\text { Atmospheric } \\ \text { Measurement } \\ \text { Techniques } \\ \hline\end{array}$

Discussions

(c) (i)

5

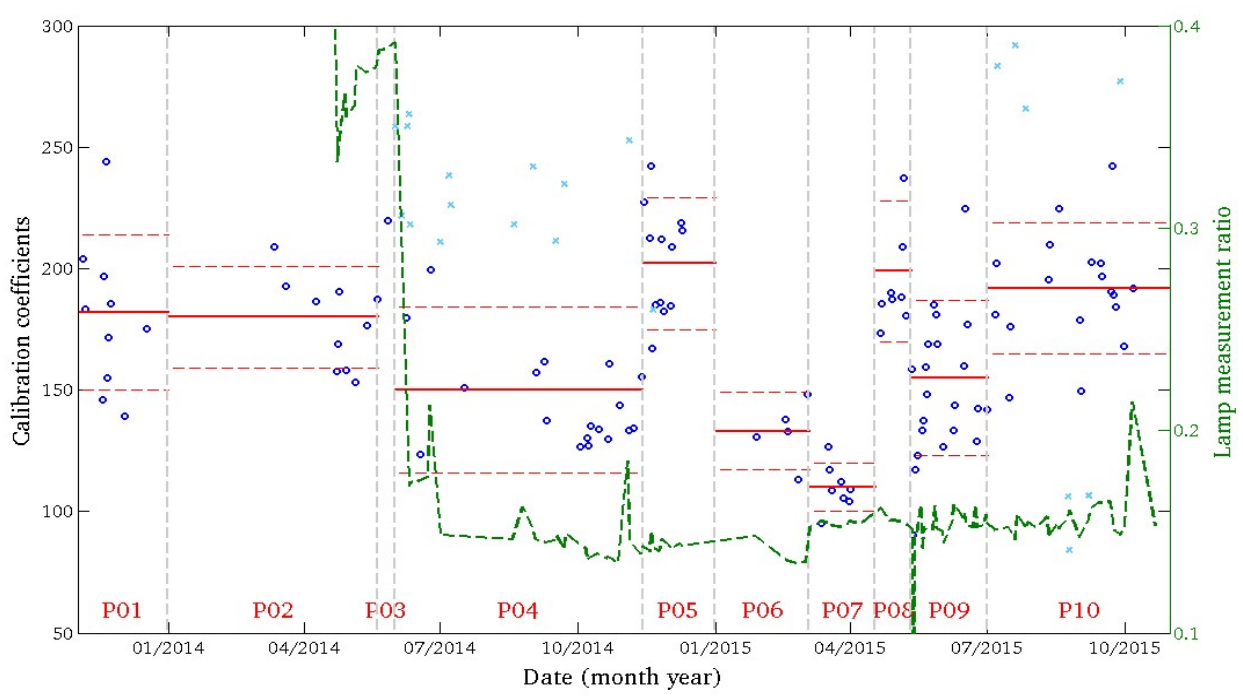

20

Figure 2. Time series of the calibration coefficient (average for the whole night of hourly coefficients, i.e. nightly coefficients, blue circles and crosses) for the Lidar1200 2-years dataset. The green dotted line corresponds to the lamp measurements realized at the beginning of each night measurement from April 2014. The vertical dotted lines separate the ten quasi-stationary periods (P01 to P10) of the calibration 25 coefficient. Horizontal solid red segments display values of the average nightly coefficient over the corresponding quasi-stationary periods, i.e. the calibration coefficient. Outliers (sky blue crosses) are not taken into account for the calculation of the average. The horizontal dotted red segments correspond to values of the mean nightly coefficients plus or minus the standard deviation. 
Atmos. Meas. Tech. Discuss., doi:10.5194/amt-2017-32, 2017

Manuscript under review for journal Atmos. Meas. Tech.

Discussion started: 4 April 2017

(c) Author(s) 2017. CC-BY 3.0 License.

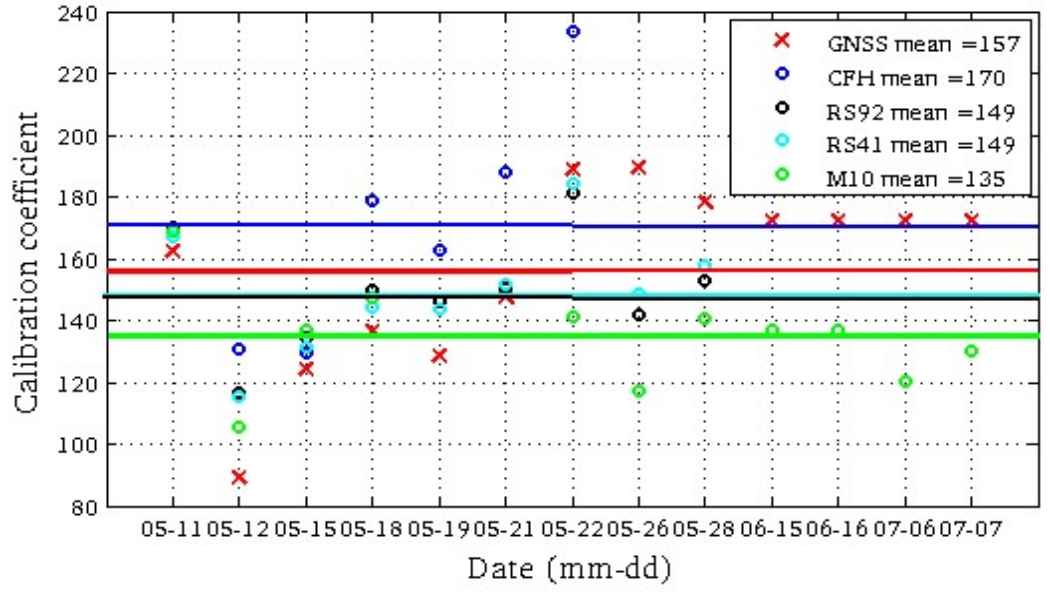

Figure 3. Time series of the Lidar1200's nightly coefficients calculated with CFH (blue), RS92 (black), RS41 (cyan), M10 (green), and

20 GNSS IWV (red). The solid lines represent the mean calibration coefficient based on each measurement technique during the MORGANE campaign. 
Atmos. Meas. Tech. Discuss., doi:10.5194/amt-2017-32, 2017

Manuscript under review for journal Atmos. Meas. Tech.

Discussion started: 4 April 2017

(c) Author(s) 2017. CC-BY 3.0 License.

(c) (1)
Atmospheric Measurement

Techniques

Discussions

5

10

15

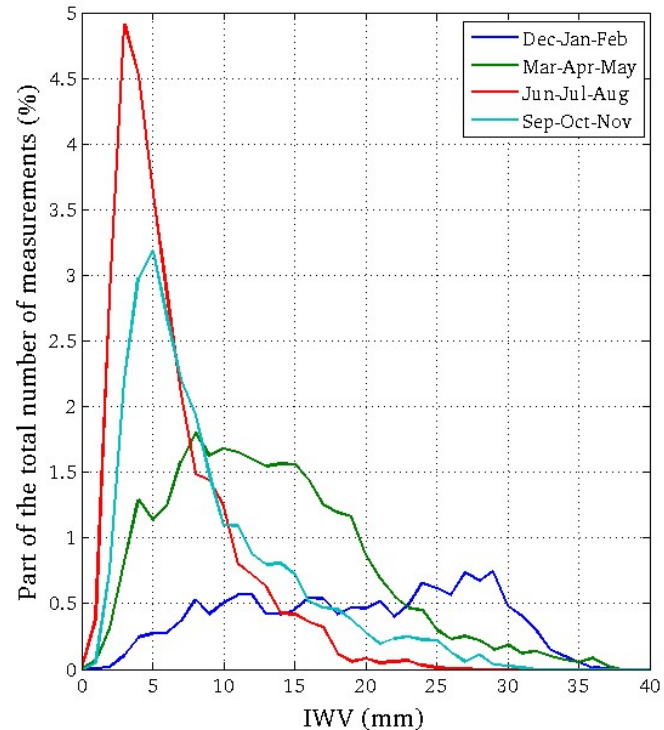

20

Figure 4. GNSS IWV distribution depending on the total number of measurements by season (in blue for the austral summer, in green for the autumn, in red for winter and in cyan for spring). 
Atmos. Meas. Tech. Discuss., doi:10.5194/amt-2017-32, 2017

Manuscript under review for journal Atmos. Meas. Tech.

Discussion started: 4 April 2017

(c) Author(s) 2017. CC-BY 3.0 License.

Atmospheric

5

10

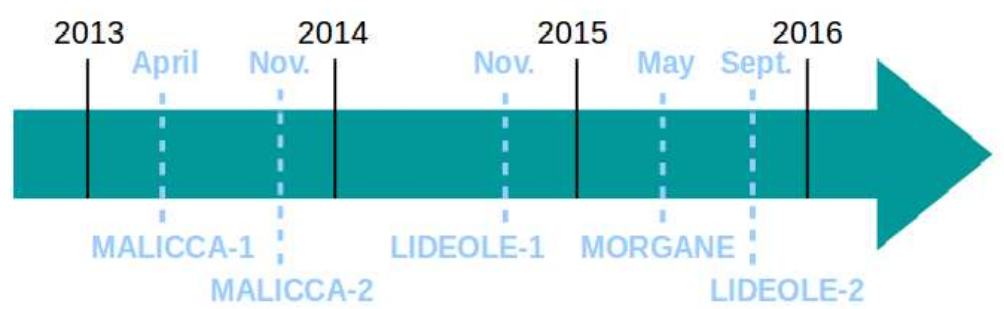

15 Figure 5. Chronological presentation of the measurement campaigns in which the Lidar1200 was involved between 2013 and 2015.

20

25

30

35

40 
Atmos. Meas. Tech. Discuss., doi:10.5194/amt-2017-32, 2017

Manuscript under review for journal Atmos. Meas. Tech.

Discussion started: 4 April 2017

(C) Author(s) 2017. CC-BY 3.0 License.

Atmospheric
Measurement
Techniques

Discussions

\section{(c) (i)}

(A)

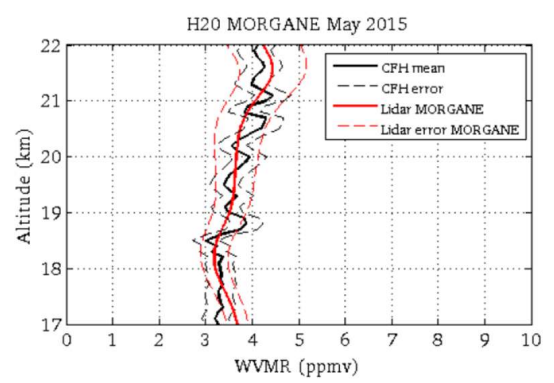

(B)

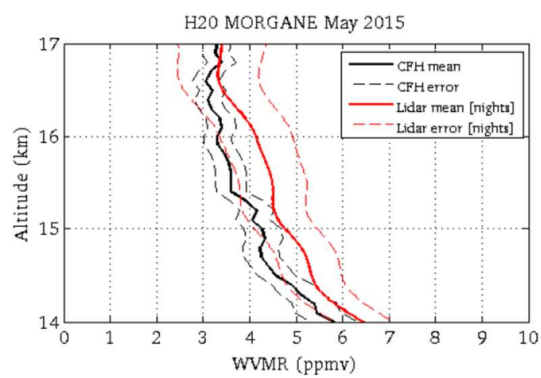

(C)

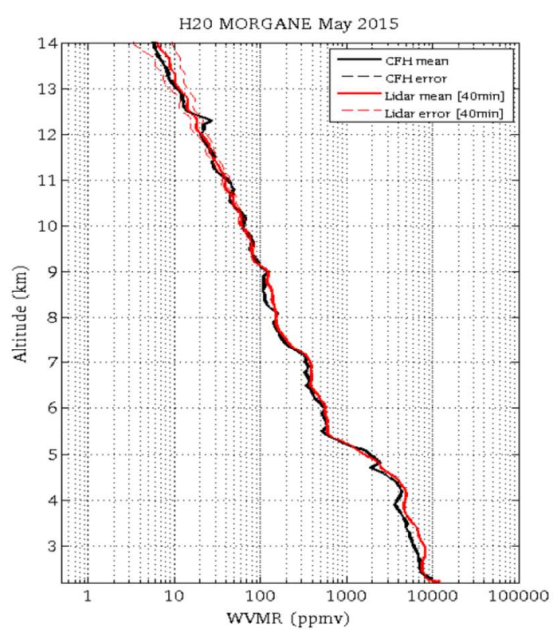

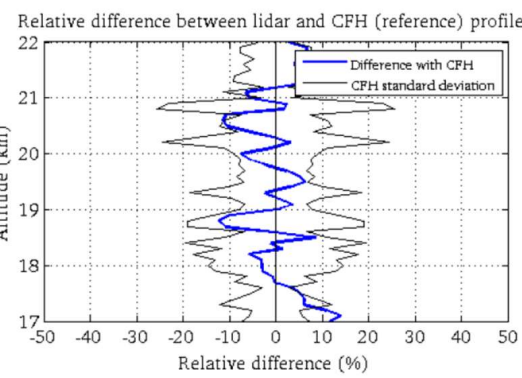

(a)

(b)

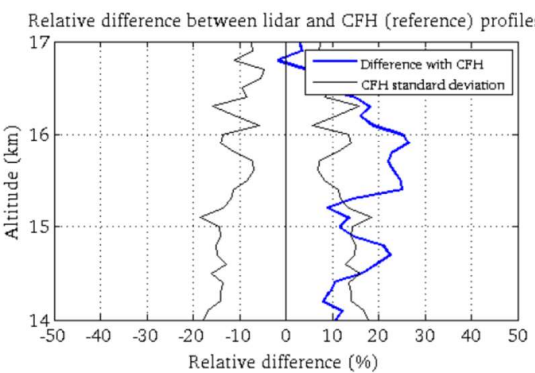

(c)

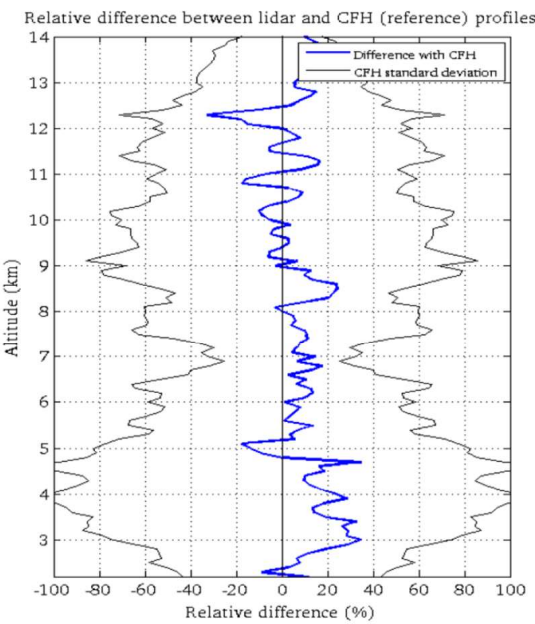

Figure 6. Comparison of the lidar and $\mathrm{CFH}$ water vapor mixing ratio during MORGANE between $2.2 \mathrm{~km}$ and $22 \mathrm{~km}$. On the left: superimposition of the mean CFH water vapor profile (thick solid black line) with the lidar profile (solid red line). At the bottom: the mean profile of the 40-min sessions between 2.2 and $14 \mathrm{~km}$ asl, in the middle: the mean lidar profile of the night sessions between 14 and $17 \mathrm{~km}$ 5 asl, and at the top: the lidar profile integrated over the whole campaign data between 17 and $22 \mathrm{~km}$ asl. The red dotted line represents the $+/-$ $1 \sigma$ lidar total error and the black one represents an uncertainty of $5 \%$ for the CFH. On the right: relative difference (in $\%$ ) between the lidar and $\mathrm{CFH}$ profiles. CFH data are taken as reference. The $\mathrm{CFH}$ standard deviation is indicated in thin black solid lines. 
Atmos. Meas. Tech. Discuss., doi:10.5194/amt-2017-32, 2017

Manuscript under review for journal Atmos. Meas. Tech.

Discussion started: 4 April 2017

(c) Author(s) 2017. CC-BY 3.0 License.

\section{(c) (i)}

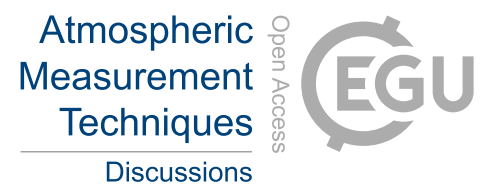

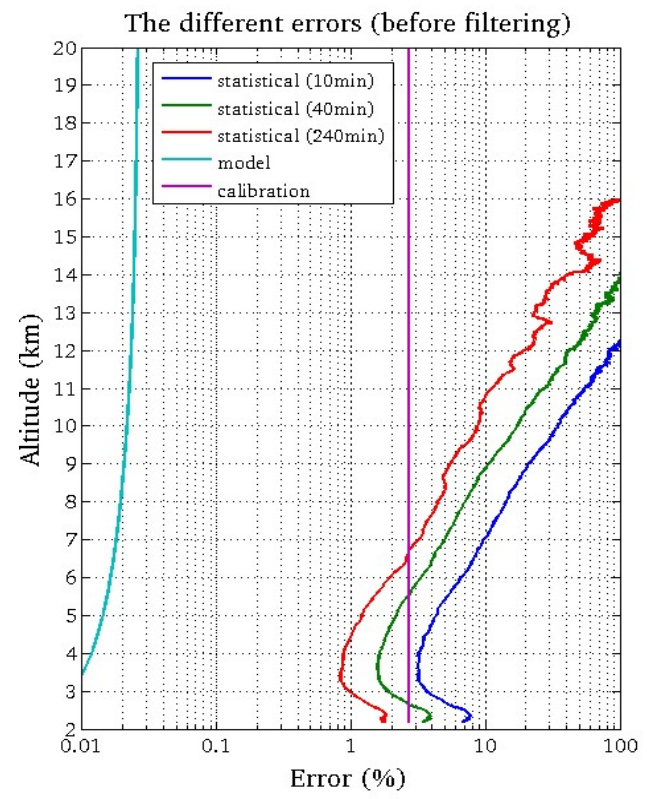

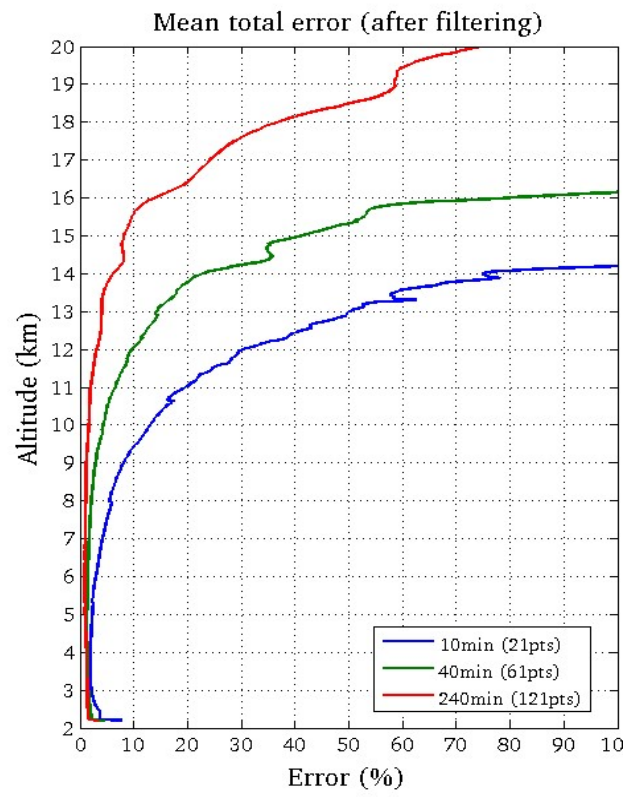

Figure 7. Contribution of the different statistical and systematic errors (left) and the total error (right) for a mean lidar profile integrated on 10 (in blue), 40 (in green) and 240 (in red) minutes according to the altitude above sea level. 
Atmos. Meas. Tech. Discuss., doi:10.5194/amt-2017-32, 2017

Manuscript under review for journal Atmos. Meas. Tech.

Discussion started: 4 April 2017

(c) Author(s) 2017. CC-BY 3.0 License.

(c) (i)
Atmospheric Measurement Techniques Discussions

5

10

15

20

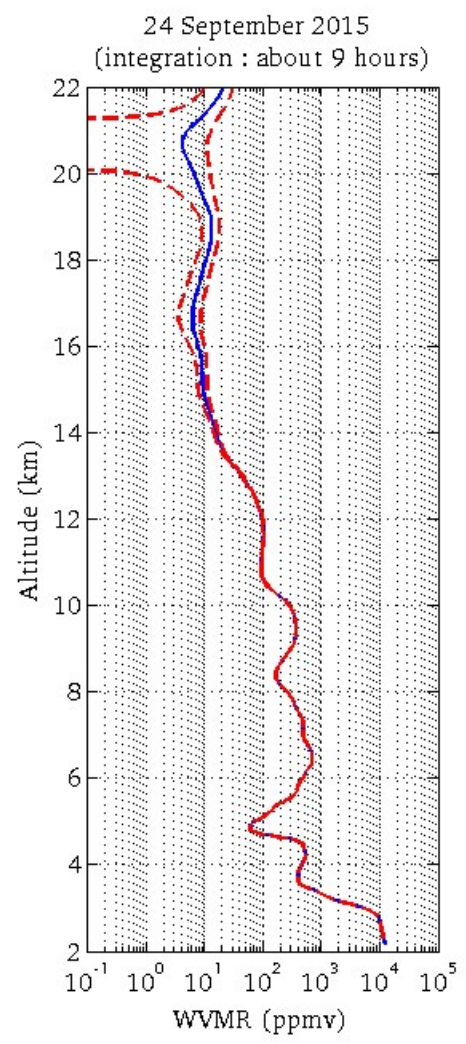

Figure 8. Water vapor mixing ratio on 24 September 2015 retrieved by the Lidar1200 (in blue) at 15:07 UTC for 531 minutes of integration between 2.2 and $24 \mathrm{~km}$ asl. The dotted red lines represent the $+/-1 \sigma$ lidar total error.

30 
Atmos. Meas. Tech. Discuss., doi:10.5194/amt-2017-32, 2017

Manuscript under review for journal Atmos. Meas. Tech.

Discussion started: 4 April 2017

(c) Author(s) 2017. CC-BY 3.0 License.

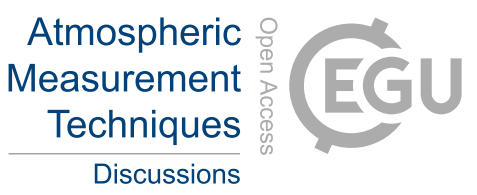

(c) (i)

5
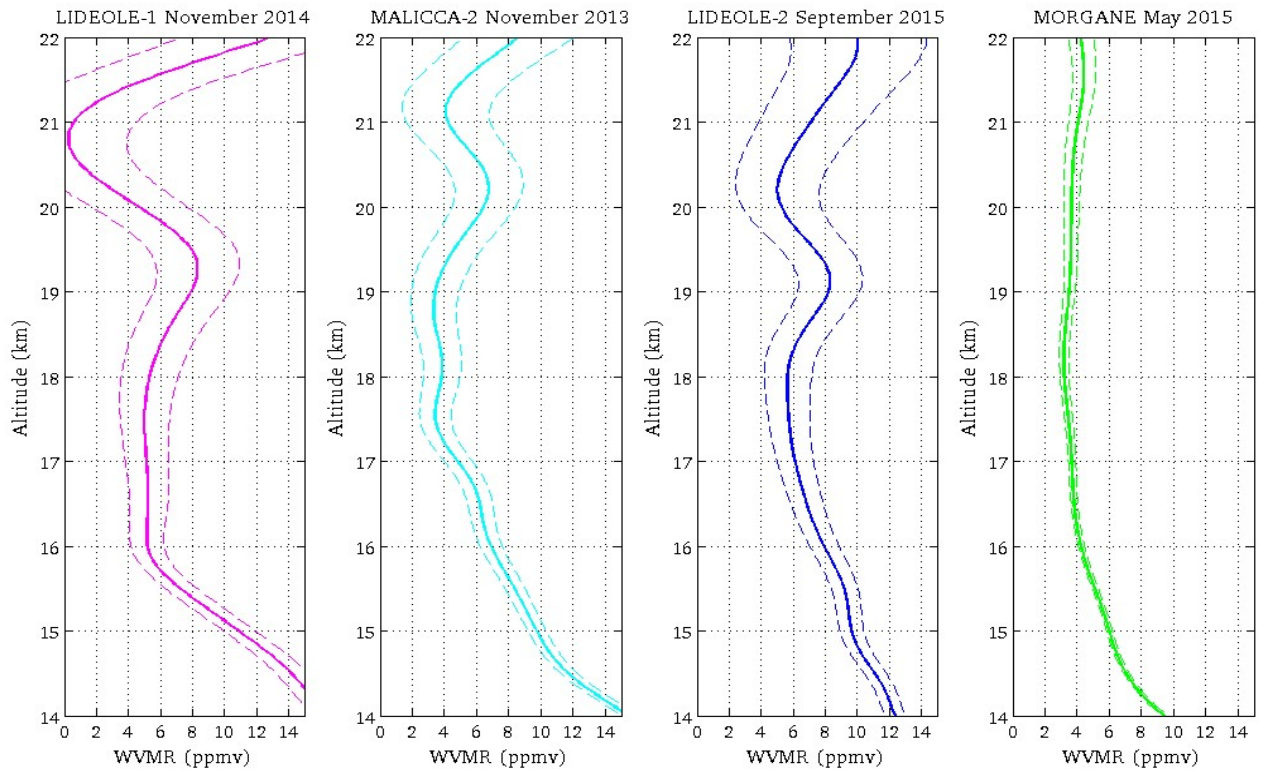

20

Figure 9. Water vapor mixing ratio profiles integrating all the data of each campaign: LIDEOLE-1 (in magenta) with about $12 \mathrm{~h}$ of data, MALICCA-2 (in cyan) with about $24 \mathrm{~h}$ of data, LIDEOLE-2 (in blue) with about $32 \mathrm{~h}$ of data and MORGANE (in green) with about $47 \mathrm{~h}$ of data, between 2.2 and $22 \mathrm{~km}$ asl. The dotted lines represent the $+/-1 \sigma$ lidar error. The filter reaches 201 points. 
Atmos. Meas. Tech. Discuss., doi:10.5194/amt-2017-32, 2017

Manuscript under review for journal Atmos. Meas. Tech.

Discussion started: 4 April 2017

(c) Author(s) 2017. CC-BY 3.0 License.

Atmospheric

5

10

15

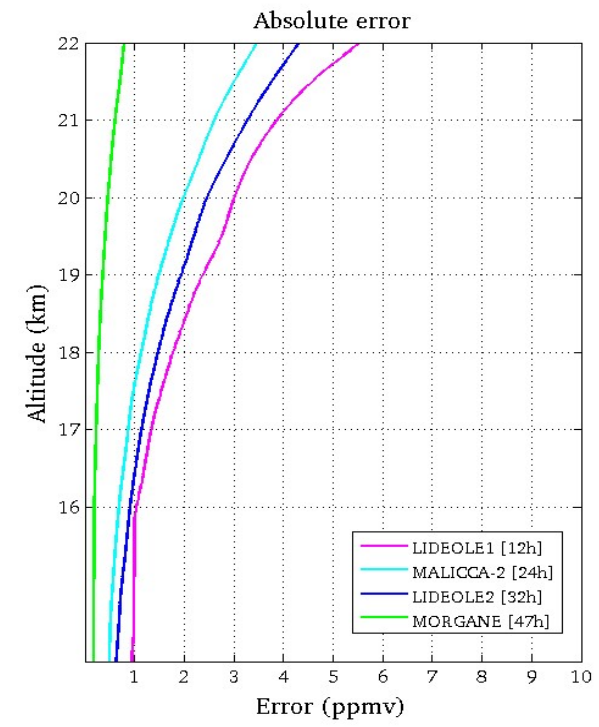

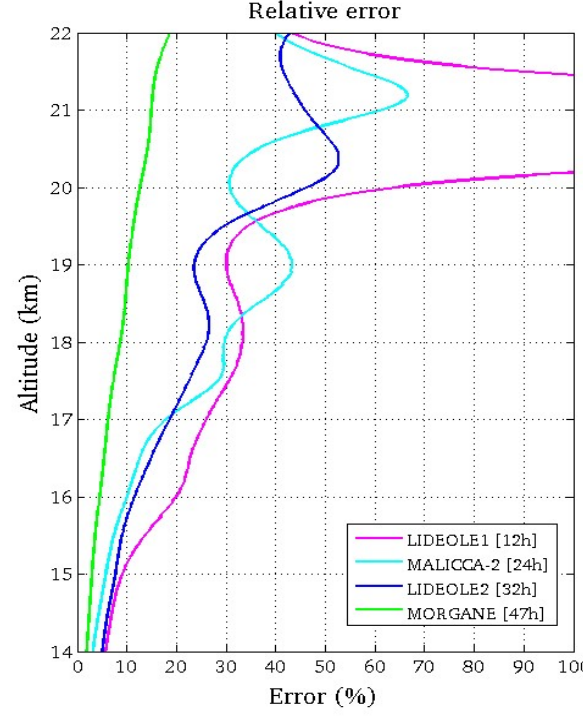

20 Figure 10. Absolute (on the left) and relative (on the left) errors of the campaigns profiles of Figure 9, between 14 and $22 \mathrm{~km}$ asl. The colors are the same than those of Figure 9. 
Atmos. Meas. Tech. Discuss., doi:10.5194/amt-2017-32, 2017

Manuscript under review for journal Atmos. Meas. Tech.

Discussion started: 4 April 2017

(C) Author(s) 2017. CC-BY 3.0 License.

\section{Atmospheric Measurement Techniques \\ Discussions}

5

10

15

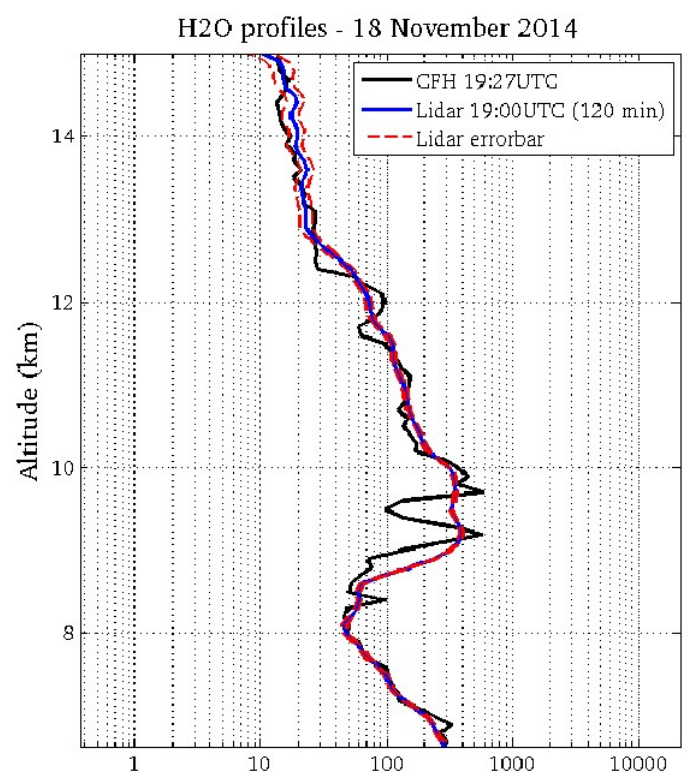

20

Water vapor mixing ratio (ppmv)

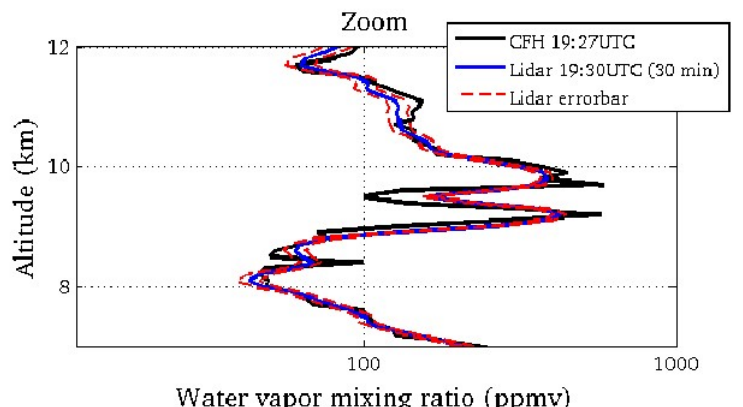

30

Figure 11. Water vapor mixing ratio profiles on 18 November 2014: CFH sonde (black line, 19:27 UTC) and Lidar1200 profile (in blue) for (top) a 120-min integration (starting at 19:00 UTC) and a 61 points filter between 2.2 and $18 \mathrm{~km}$ asl and (bottom) a 30-min integration 35 (starting at 19:30 UTC) and a 21 points filter between 7.5 and $12 \mathrm{~km}$ asl. The red dotted lines represent the $+/-1 \sigma$ lidar total error.

40 
Atmos. Meas. Tech. Discuss., doi:10.5194/amt-2017-32, 2017

Manuscript under review for journal Atmos. Meas. Tech.

Discussion started: 4 April 2017

(c) Author(s) 2017. CC-BY 3.0 License.
Atmospheric Measurement

Techniques

Discussions

5

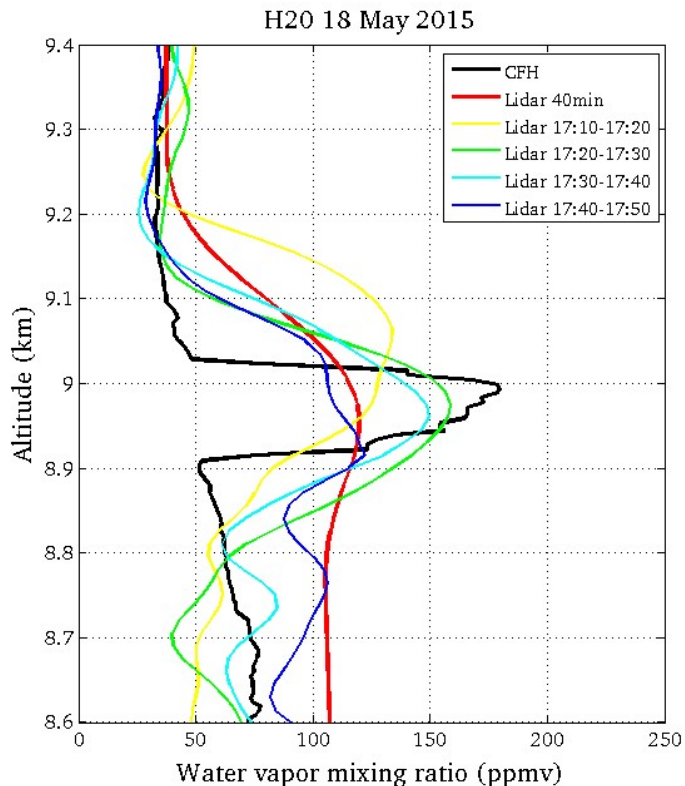

20

Figure 12. Water vapor mixing ratio profiles on 18 May 2015, CFH (17:16 UTC; in black) and Lidar1200 (17:15 UTC for a 40-min integration in red with a filter of 61 points and by 10 -minutes step in colors with a filter of 21 points).

25 
Atmos. Meas. Tech. Discuss., doi:10.5194/amt-2017-32, 2017

Manuscript under review for journal Atmos. Meas. Tech.

Discussion started: 4 April 2017

(c) Author(s) 2017. CC-BY 3.0 License.

(c) (1)
Atmospheric Measurement

Techniques

Discussions

5

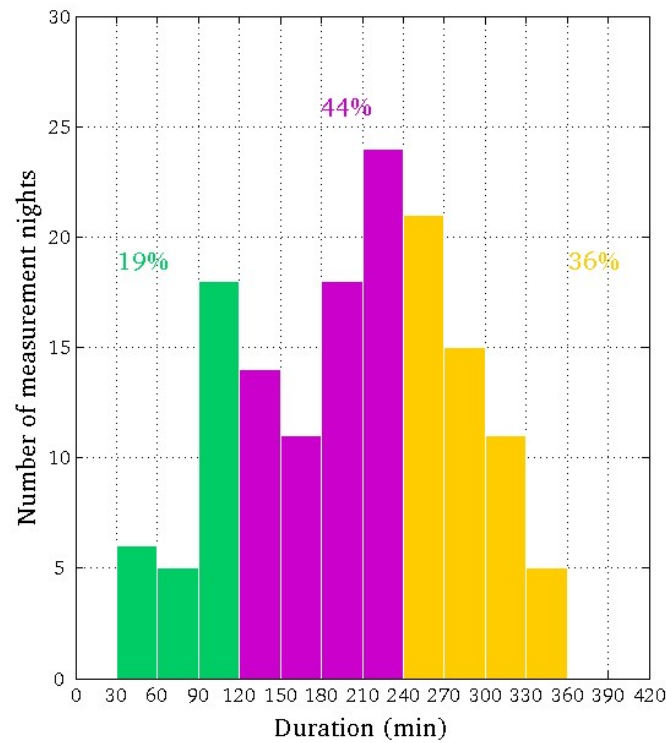

20

Figure 13. Distribution of the Lidar1200 water vapor measurement sessions with respect to the integration time (duration in minutes). 
Atmos. Meas. Tech. Discuss., doi:10.5194/amt-2017-32, 2017

Manuscript under review for journal Atmos. Meas. Tech.

Discussion started: 4 April 2017

(c) Author(s) 2017. CC-BY 3.0 License.

\section{Atmospheric Measurement \\ Techniques}

Discussions

5

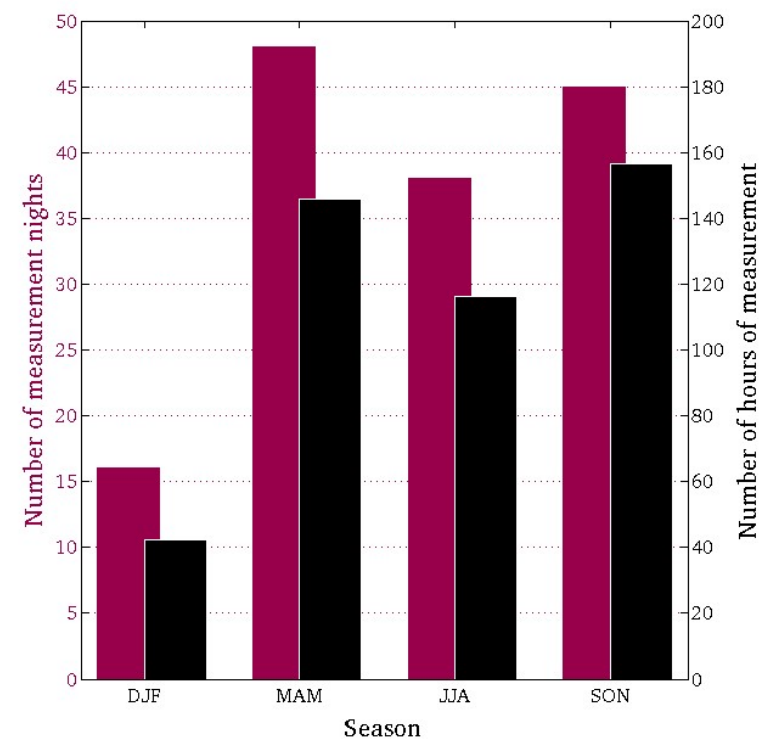

Figure 14. Distribution of the Lidar 1200 water vapor data depending on the seasons. Black bars represent the number of hours of measurements. Fuchsia bars represent the nights of measurements.

25 
Atmos. Meas. Tech. Discuss., doi:10.5194/amt-2017-32, 2017

Manuscript under review for journal Atmos. Meas. Tech.

Discussion started: 4 April 2017

(c) Author(s) 2017. CC-BY 3.0 License.

\section{Atmospheric \\ Measurement \\ Techniques}

Discussions

5

10

15

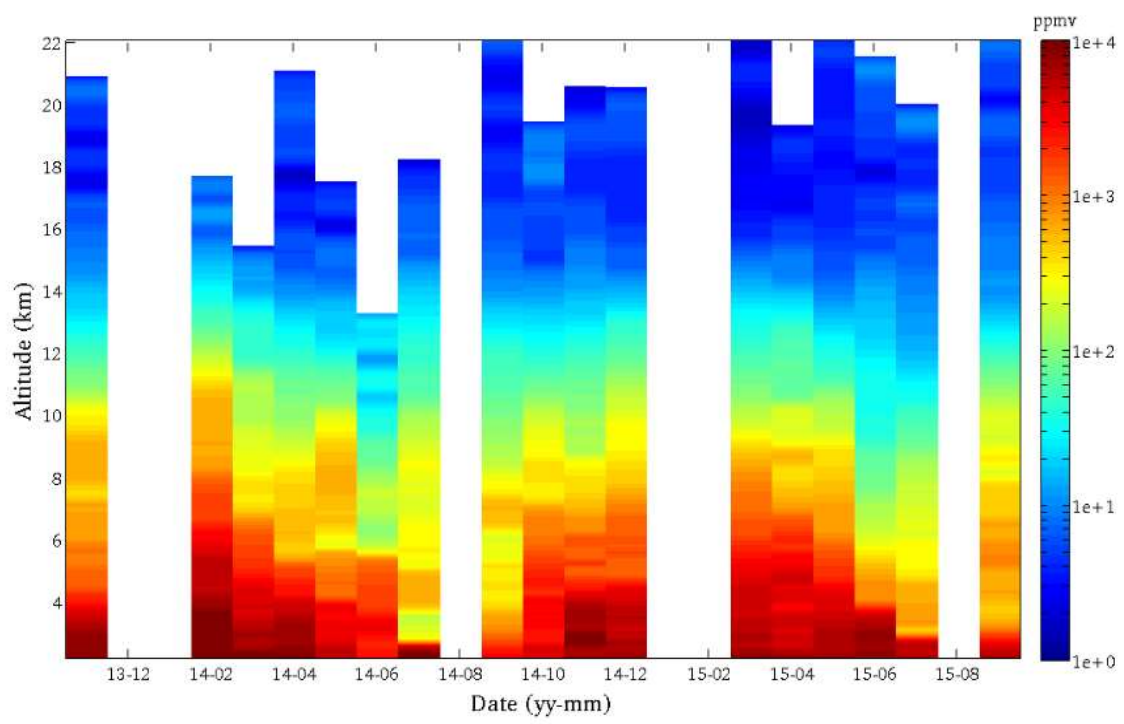

20

Figure 15. Time series of the water vapor Lidar 1200 monthly profiles from November 2013 to October 2015. Lidar session of 8-hours minimum are required to build a monthly profile and the data for which the total error is higher than $80 \%$ are not taken into account. The abscissa indicates the month and the year of the profile. 
Atmos. Meas. Tech. Discuss., doi:10.5194/amt-2017-32, 2017

Manuscript under review for journal Atmos. Meas. Tech.

Discussion started: 4 April 2017

(C) Author(s) 2017. CC-BY 3.0 License.
Atmospheric Measurement Techniques Discussions (c) (1)

\begin{tabular}{|c|c|c|c|c|}
\hline PERIOD & DATES & $\begin{array}{c}\text { CALIBRATION } \\
\text { COEFFICIENT }\end{array}$ & $\begin{array}{c}\text { ABSOLUTE } \\
\text { ERROR }\end{array}$ & $\begin{array}{c}\text { RELTIVE } \\
\text { ERROR } \\
(\%)\end{array}$ \\
\hline 01 & $01 / 11 / 2013-31 / 12 / 2013$ & 182 & 5 & 3 \\
\hline 02 & $01 / 01 / 2014-20 / 05 / 2014$ & 180 & 4 & 2 \\
\hline 03 & $21 / 05 / 2014-31 / 05 / 2014$ & Not defined & Not defined & Not defined \\
\hline 04 & $01 / 06 / 2014-16 / 11 / 2014$ & 150 & 5 & 3 \\
\hline 05 & $17 / 11 / 2014-31 / 12 / 2014$ & 202 & 6 & 3 \\
\hline 06 & $01 / 01 / 2015-04 / 03 / 2015$ & 133 & 5 & 4 \\
\hline 07 & $05 / 03 / 2015-17 / 04 / 2015$ & 110 & 2 & 2 \\
\hline 08 & $18 / 04 / 2015-10 / 05 / 2015$ & 199 & 7 & 4 \\
\hline 09 & $11 / 05 / 2015-01 / 07 / 2015$ & 155 & 4 & 3 \\
\hline 10 & $02 / 07 / 2015-31 / 10 / 2015$ & 192 & 3 & 2 \\
\hline
\end{tabular}

Table 1. Recap chart of the different calibration coefficients of the water vapor data of the Lidar 1200 between November 2013 and October 2015.

5 
Atmos. Meas. Tech. Discuss., doi:10.5194/amt-2017-32, 2017

Manuscript under review for journal Atmos. Meas. Tech.

Discussion started: 4 April 2017

(c) Author(s) 2017. CC-BY 3.0 License.
Atmospheric Measurement Techniques

Discussions

(c) (i)

\begin{tabular}{|c|c|c|c|c|}
\hline $\begin{array}{c}\text { NAME OF THE } \\
\text { CAMPAIGN }\end{array}$ & LIDEOLE-1 & MALICCA-2 & LIDEOLE-2 & MORGANE \\
\hline $\begin{array}{r}\text { DURATION OF } \\
\text { THE CAMPAIGN }\end{array}$ & 4 nights & 6 nights & 10 nights & 18 nights \\
\hline $\begin{array}{r}\text { TOTAL OF THE } \\
\text { MESUREMENTS }\end{array}$ & 12 hours & 24 hours & 32 hours & 47 hours \\
\hline $\begin{array}{r}\text { ALTITUDE AT 2 } \\
\text { PPMV ABSOLUTE }\end{array}$ & $18.5 \mathrm{~km}$ & 6 nights & 6 nights & 12 nights \\
\hline $\begin{array}{r}\text { ERROR } \\
\hline \text { RELATIVE ERROR }\end{array}$ & $30 \%$ & $20 \mathrm{~km}$ & $19.1 \mathrm{~km}$ & $>22 \mathrm{~km}$ \\
\hline
\end{tabular}

Table 2. Main characteristics of the water vapor profiles of Figure 9. The duration of the campaign corresponds to the number of nights between the beginning and the end of the campaign (including the nights with no lidar shot). The total of measurements corresponds to the total number of hours or nights of measurements integrated for the profile. The vertical resolution of the profiles is $1.3 \mathrm{~km}$. 
Atmos. Meas. Tech. Discuss., doi:10.5194/amt-2017-32, 2017

Manuscript under review for journal Atmos. Meas. Tech.

Discussion started: 4 April 2017

(c) Author(s) 2017. CC-BY 3.0 License.
Atmospheric Measurement Techniques Discussions (c) (i)

10

\begin{tabular}{|c|c|c|c|}
$\begin{array}{c}\text { ALTITUDE } \\
\text { RANGE (km asI) }\end{array}$ & $\begin{array}{c}\text { INTEGRATION } \\
\text { TIME (min) }\end{array}$ & $\begin{array}{c}\text { FILTER (number } \\
\text { of points) }\end{array}$ & $\begin{array}{c}\text { VERTICAL } \\
\text { RESOLUTION } \\
(\mathbf{m})\end{array}$ \\
\hline $2.2-5$ & 1 & 21 & 65 \\
\hline $2.2-10$ & $5-10$ & 21 & $65-90$ \\
\hline $2.2-14$ & 40 & 61 & $100-300$ \\
\hline $2.2-17$ & $240-480$ & 121 & $100-650$ \\
\hline $2.2-22$ & $>480$ & 201 & $150-1300$ \\
\hline
\end{tabular}

Table 3. User's guide for the Lidar 1200 water vapor data treatment regarding the altitude range. 
Atmos. Meas. Tech. Discuss., doi:10.5194/amt-2017-32, 2017

Manuscript under review for journal Atmos. Meas. Tech.

Discussion started: 4 April 2017

(c) Author(s) 2017. CC-BY 3.0 License.

Atmospheric

\begin{tabular}{|c|c|c|c|}
\hline $\begin{array}{c}\text { ALTITUDE } \\
\text { RANGE }(\mathrm{km} \text { asI) }\end{array}$ & $\begin{array}{c}\text { TEMPORAL } \\
\text { RESOLUTION } \\
(\mathrm{min})\end{array}$ & $\begin{array}{c}\text { VERTICAL } \\
\text { RESOLUTION } \\
(\mathrm{m})\end{array}$ & ERROR $(\%)$ \\
\hline $2.2-10$ & 10 & $65-90$ & $<15$ \\
\hline $2.2-14$ & 40 & $100-300$ & $<20$ \\
\hline $2.2-17$ & $240-480$ & $100-650$ & $<20$ \\
\hline $2.2-22$ & $\sim 2800$ & $150-1300$ & $<20$ \\
\hline
\end{tabular}

10

Table 4. Level 2 water vapor profiles that can be provided by the Lidar1200 to international networks (and users on demand) 